\title{
Can hypochlorous acid be a powerful sanitizer to replace alcohol for disinfection? - Its bactericidal, degradation of the solutions under various storage condition, and steel rust effects
}

\author{
Takashi KAMEDA ${ }^{1}$, Shunya OKA², Jun-ichi IGAWA ${ }^{3}$, Makoto SAKAMOTO ${ }^{4}$ and Kazuto TERADA ${ }^{5}$ \\ ${ }^{1}$ Department of Orthodontics, Nippon Dental University School of Life Dentistry at Niigata, 1-8 Hamaura-cho, Chuo-ku, Niigata 951-8580, Japan \\ ${ }^{2}$ Department of Biology, Nippon Dental University School of Life Dentistry at Niigata, 1-8 Hamaura-cho, Chuo-ku, Niigata 951-8580, Japan \\ ${ }^{3}$ Igawa Dental Office, 7-14-16 Oizumigakuen-cho, Nerima-ku, Tokyo 178-0061, Japan \\ ${ }^{4}$ Department of Health Sciences, Niigata University School of Medicine, 2-746, Asahimachi, Chuo-ku, Niigata 951-8518, Japan \\ ${ }^{5}$ Nippon Dental University Niigata Hospital, 1-8 Hamaura-cho, Chuo-ku, Niigata 951-8580, Japan \\ Corresponding author, Takashi KAMEDA; E-mail: tkameda_jbso@yahoo.co.jp
}

\begin{abstract}
Coronavirus disease pandemic has led to a shortage of disinfectant alcohol (DA; 76.9-81.4\% ethanol solution) in Japan. This study investigated the availability of hypochlorous acid (HA) as an alternative disinfectant to DA in clinical environment. HA is a safe and economical disinfectant with a broad antibacterial spectrum and low risk of hand irritation, which is used worldwide. In this study, HA and sodium hypochlorite solution (SH) were degraded over time and the degradation was accelerated by temperature and lighting. Results of bactericidal effects of HA revealed that the realistic effective concentration should be 200 ppm. Compared with DA, the dental carbon steel burs were more severely rusted by SH and HA. These results indicated that high concentration of HA generated on-site could be an effective and safe disinfectant for use immediately after generation with consideration of object materials in clinical environment, as an alternative to DA.
\end{abstract}

Keywords: On-site generation, Ethanol, Residual chlorine concentration, pH

\section{INTRODUCTION}

Since winter 2019 to early 2020, coronavirus disease (COVID-19) has spread worldwide and this pandemic is predicted to continue until 2022-20241). This pandemic has caused shortage of masks and disinfectants, especially disinfectant alcohol (DA; 76.9-81.4\% ethanol [EtOH] solution), in all the cities, especially medical institutions, in Japan. In addition to the prevention of droplet infection with masks, ensuring social distancing, enforcement of hand washing, and disinfection of the areas touched by the hands are important for the prevention of infection. Instead of DA, several disinfectants were shortlisted and their efficacy was investigated by an independent administrative institution, National Institute of Technology and Evaluation (NITE), at the request of the Ministry of Economy, Trade, and Industry of Japan. These NITE reports indicated the possibility of substituting sterilizing supplies with surfactants and hypochlorous acid (HA) ${ }^{2}$. The US Environmental Protection Agency (EPA) recommends HA as an effective disinfectant for COVID-193), and the Center for Disease Control and Prevention (CDC) considers it a high-level disinfectant ${ }^{4)}$, and HA has been approved for clinical use $^{5,6)}$.

HA, which is often confused with strongly alkaline sodium hypochlorite (SH), is effective disinfectant with broad antibacterial spectrum for many bacteria with or without spore and viruses ${ }^{7.9}$; however, careful

Color figures can be viewed in the online issue, which is available at J-STAGE.

Received May 12, 2021: Accepted Jul 27, 2021

doi:10.4012/dmj.2021-146 JOI JST.JSTAGE/dmj/2021-146 handling is required. Ultraviolet (UV) light and high temperature are known to degrade HA rapidly ${ }^{10,11}$. Therefore, disinfectant effects of these reagents are often highly variable and inconsistent, especially when using commercially available bottled HA with unknown information regarding their storage after manufacture ${ }^{12)}$. HA is approved as a disinfectant for food in Japan, but can only be used fresh out of the generator ${ }^{13)}$. There are three types of generators for HA: electrolysis (EL), twoliquid mixture $(2 \mathrm{Mx})$, and carbon dioxide mixture $\left(\mathrm{CO}_{2}\right)$ type (Fig. 1). Since the $2 \mathrm{Mx}$ type (mixture of $\mathrm{SH}$ and acidic solution as a $\mathrm{pH}$ regulator) may generate chlorine (Cl) gas during the HA generation process at low $\mathrm{pH}$ $(<\mathrm{pH} 4)$ in mixing stages, which can cause fatalities, EL or $\mathrm{CO}_{2}$ type generators can be used in general facilities and medical institutions for on-site generation.

HA has strong oxidizing reagents that should be considered as one of the alternatives to DA. However, its poor shelf life and difficulty in storage could be a problem for its use. Therefore, one of the basic requirements for use of HA is to have a proper generator in possession. Hence, these reagents are not widely used presently in clinical environment.

In this study, we investigated whether HA can be used as an alternative disinfectant to DA in medical and dental practice; its disinfecting effects in the presence of organic matter, and dental carbon steel burs used in clinical field, and the degradation of reagents during storage directly related to its disinfecting effects, compared with DA. 

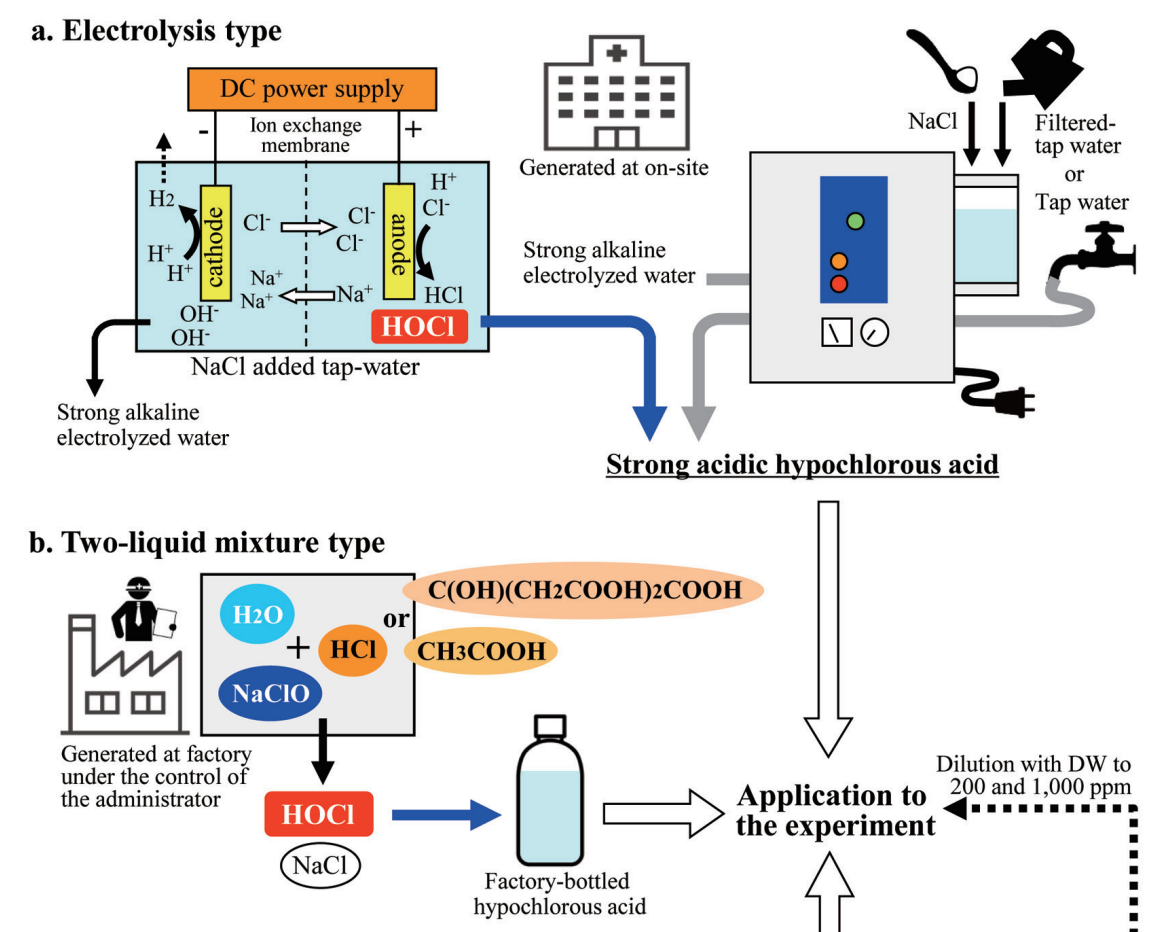

c. Carbon dioxide mixture type

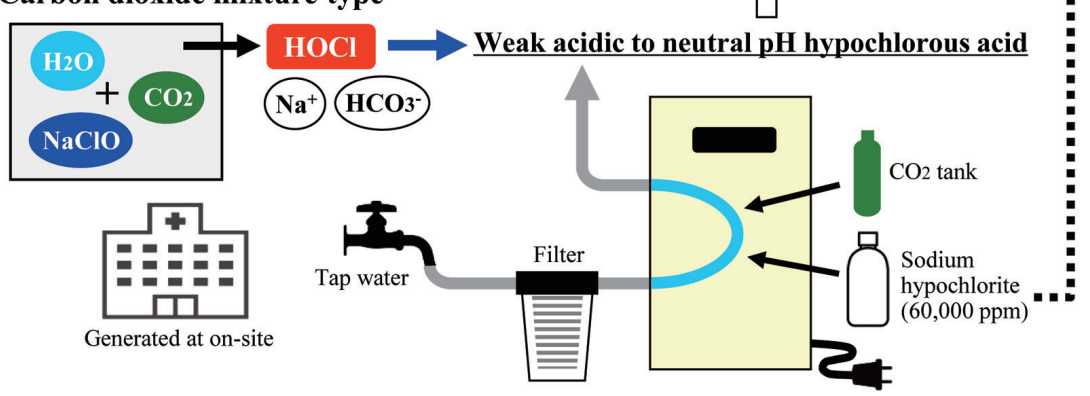

Fig. 1 Three types of generation methods of hypochlorous acid.

(a) Electrolysis type, (b) Two-liquid mixture type, (c) Carbon dioxide mixture type. DW; distilled water, $\mathrm{CO}_{2}$; carbon dioxide

\section{MATERIALS AND METHODS}

\section{Materials}

We prepared $\mathrm{SH}$ and three types of $\mathrm{HA}$ as an alternative disinfectant to DA (76.9-81.4\% EtOH solution, $80 \%$ was selected in this study). SH at 200 and $1,000 \mathrm{ppm}$ was prepared by 300 and 60 fold-dilution of $6 \% \mathrm{SH}$ solution (Purelox, Oyalox, Tokyo, Japan) with distilled water (DW), respectively. These are the recommended concentrations of $\mathrm{SH}^{14)}$ : $200 \mathrm{ppm}$ for wiping of usual equipment and instruments and 1,000 ppm for equipment exposed to vomit, feces, saliva, and other body fluids. The EL type HA was prepared by electrolysis of $\mathrm{NaCl}-$ added tap water using a generator (Fineoxer FOW1000S6-D/G, First Ocean, Kanagawa, Japan) at on-site. The 2Mx type HA was commercially available in bottled products (Product A; Cl concentration: not mentioned,
$\mathrm{pH}$ : weak acidity, $\mathrm{pH}$ regulator; $\mathrm{CH}_{3} \mathrm{COOH}$, Product $\mathrm{B}$; $\mathrm{Cl}$ concentration: $50 \mathrm{ppm}, \mathrm{pH}$ 6.5, $\mathrm{pH}$ regulator; $\mathrm{HCl}$, Product $\mathrm{C}$; $\mathrm{Cl}$ concentration: $100 \mathrm{ppm}, \mathrm{pH}$ 5.0-6.5, $\mathrm{pH}$ regulator, Product D; Cl concentration: 100 ppm, pH 6.5, $\mathrm{pH}$ regulator; $\mathrm{HCl}$, Product $\mathrm{E} ; \mathrm{Cl}$ concentration: $200 \mathrm{ppm}$, $\mathrm{pH}$ 6.5, pH regulator; $\mathrm{HCl}$. Bottled products $\mathrm{A}-\mathrm{D}$ were purchased through online site. Bottled product $\mathrm{E}$ was directly purchased and shipped to us in a refrigerated state immediately after generation, directly from the manufacturing plant). The $\mathrm{CO}_{2}$ type $\mathrm{HA}$ of $120 \mathrm{ppm}$ was carbonated SH diluted with tap water using a generator (KHM-1, Renafine, Tokyo, Japan). High concentration (200 ppm) of $\mathrm{CO}_{2}$ type HA was obtained from our newly developed prototype generator. Tap water of the Nippon Dental University at Niigata was used in this study (pH: 5.7-6.2, free $\mathrm{Cl}$ concentration: $0.4 \pm 0.15 \mathrm{ppm}$ ) and was filtered to remove small contaminants with a filter 
Degradation test

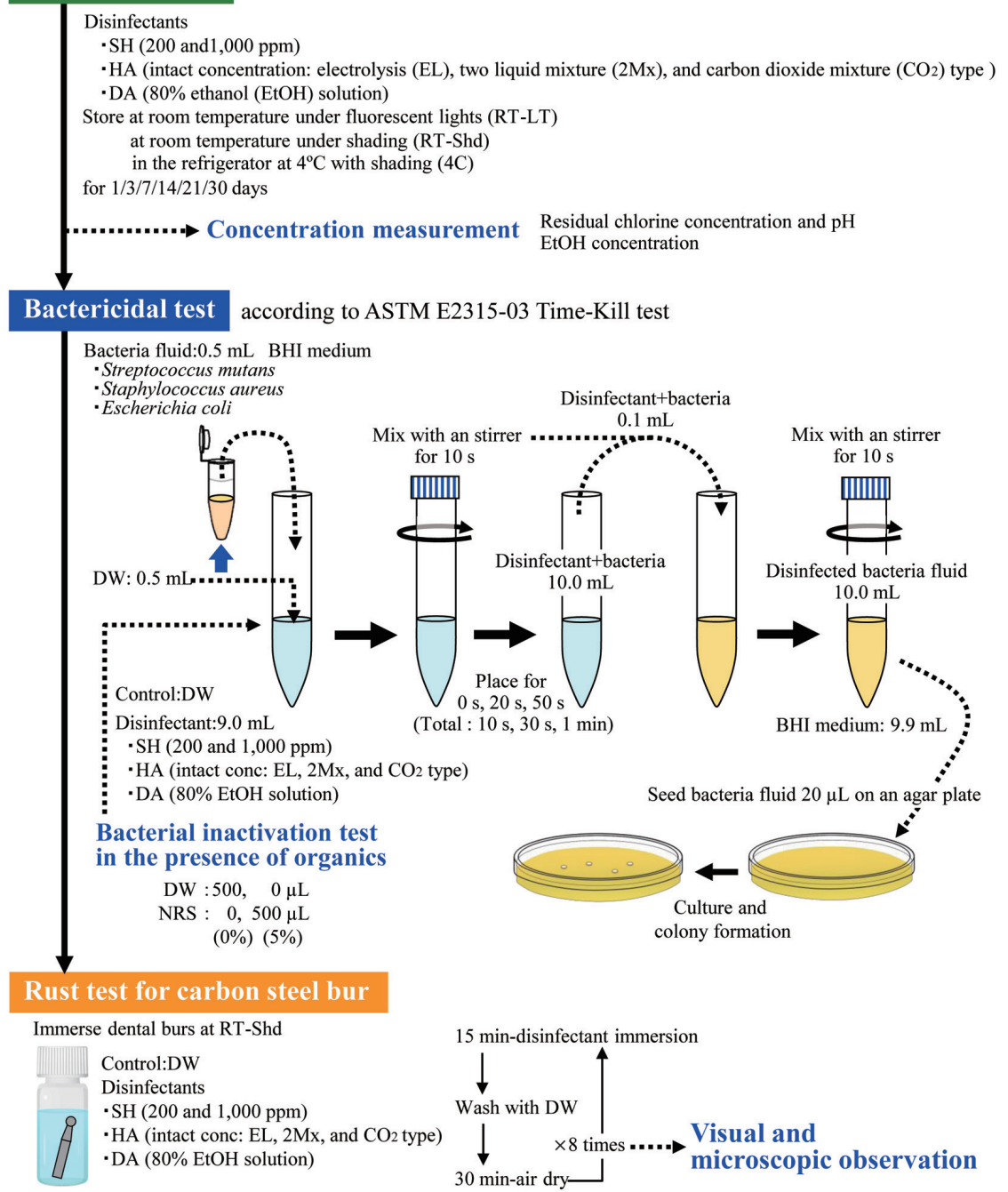

Fig. 2 Experimental flow.

DW; distilled water, DA; 80\% EtOH solution, $\mathrm{SH}$; sodium hypochlorite, HA; hypochlorous acid, NRS; normal rabbit serum

(Plastic filter housing with cartridge filter, Kankyo Technos, Wakayama, Japan), which was fed into the generator to produce HA (Fig. 2). Further, 80\% EtOH solution as DA was diluted to $99.5 \%$ EtOH (Hayashi Pure Chemical Industries, Osaka, Japan) with DW. Carbon steel burs for contra-angle dental handpieces (ELA steel bur CA 6, Shofu, Tokyo, Japan) were used for rust test of dental carbon steel burs.

\section{Specification of bottled $H A$}

Prior to following experiments, we checked the $\mathrm{pH}$ and residual $\mathrm{Cl}$ concentration (RCC) (Fig. 3) of bottled $2 \mathrm{Mx}$ type $\mathrm{HA}$ ( $\mathrm{SH}$ and $\mathrm{HCl}$ or $\mathrm{CH}_{3} \mathrm{COOH}$ ) with $\mathrm{pH}$ meter (LAQUAtwin B-71X, Horiba, Kyoto, Japan) and chlorometer (HI96771, Hanna Instruments Japan, Chiba, Japan; measurement accuracy: RCC: 1.0 ppm) respectively, to check the matches to the catalog specifications of products instructed.

\section{Storage condition-related degradation of disinfectants} $\mathrm{SH}$, three types of HA, and $80 \% \mathrm{EtOH}$ solution as DA were stored in tightly sealed clear plastic centrifugal tube $(15 \mathrm{~mL}$ solution in $15 \mathrm{~mL}$ centrifuge tube; tube material: polypropylene; cap material: polyethylene, BM Equipment, Tokyo, Japan) under the following three conditions: storage at room temperature (RT: $22.5 \pm 0.83^{\circ} \mathrm{C}$ ) with fluorescent lamp lighting (LT; illumination: $2022.5 \pm 84.01 \mathrm{~lx}$ and UV intensity: $10.7 \pm 1.21 \mu \mathrm{W} / \mathrm{cm}^{2}$ ), storage at RT with shading (Shd), and storage at $4^{\circ} \mathrm{C}$ with $\mathrm{Shd}$ (in a refrigerator [4C]). The plastic tube containing the solution was covered entirely with aluminum foil and placed in a lightproof box for Shd. Illumination and UV intensity were estimated by an illuminometer (LX2; Sanwa Electric Instrument, Tokyo, 

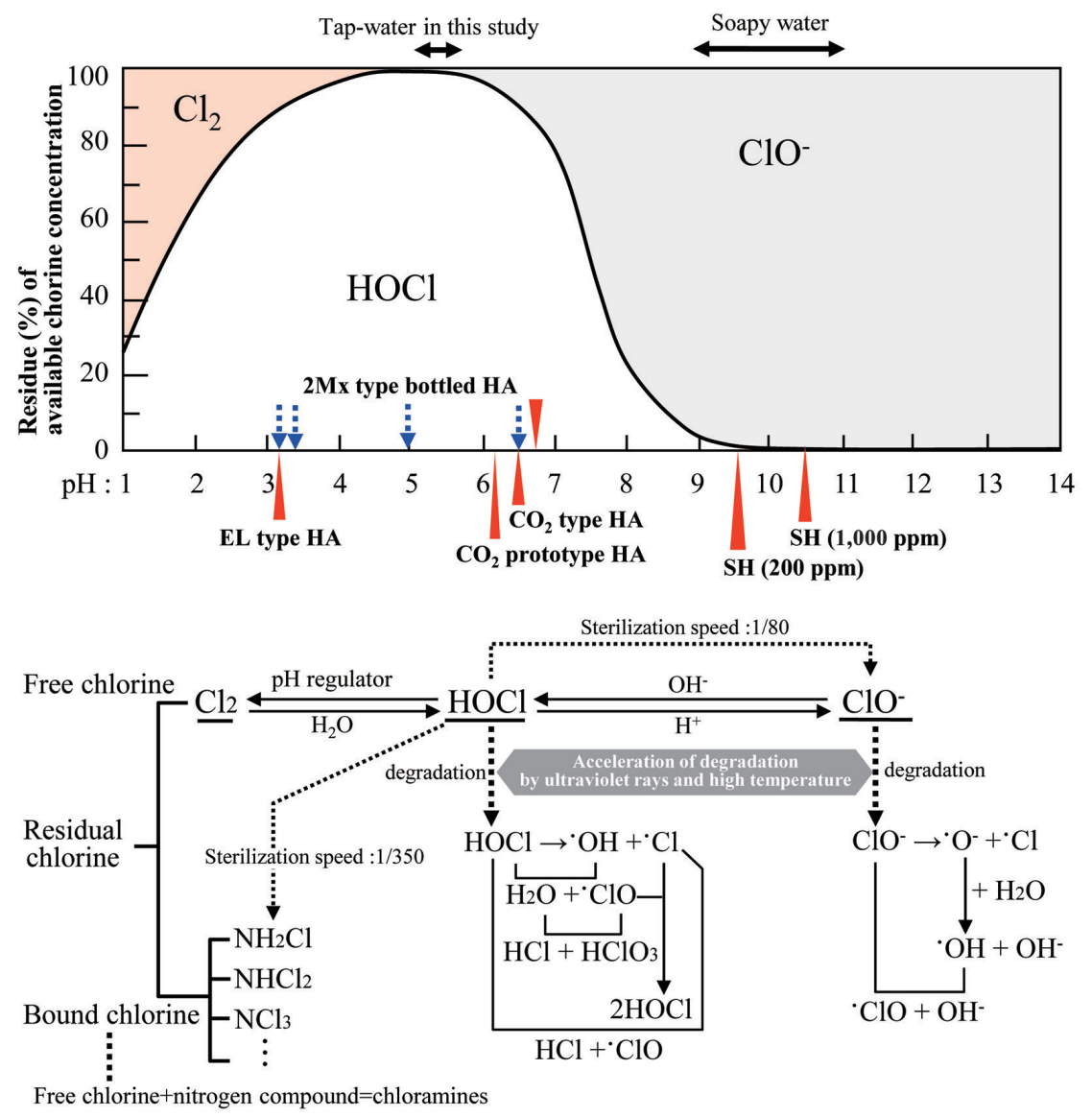

Fig. 3 State of hypochlorous acid.

$2 \mathrm{Mx}$; Two-liquid mixture type, EL; Electrolysis type, $\mathrm{CO}_{2}$; Carbon dioxide mixture type, $\mathrm{SH}$; sodium hypochlorite, HA; hypochlorous acid. Blue dotted arrows indicate $\mathrm{pH}$ of bottled commercial $2 \mathrm{Mx}$ HA used in specification check. Red solid arrows indicate $\mathrm{pH}$ of HAs used in degradation, bactericidal, and rust tests.

Japan) and UV intensity meter (SP-82UV, Mother Tool, Tochigi, Japan), respectively. The EL type and $\mathrm{CO}_{2}$ type HA produced by each generator at on-site were used at the concentration as they came out of each generator. Unadjusted concentrations of the solutions were used because matching the concentrations of each solution could have caused the disinfectant effect and $\mathrm{pH}$ to work improperly (Fig. 3). Measurement of $\mathrm{pH}$ for all solutions with a $\mathrm{pH}$ meter; RCC for $\mathrm{SH}$, each HA, and tap water with a chlorometer; and EtOH concentration with an EtOH concentration meter (PAL-corona disinfectant checker, Atago, Tokyo, Japan; measurement accuracy: $\pm 1.0 \%$ ), were performed at, before, and each storage point: 0, 1, 3, 7 (1 week), 14 (2 weeks), 21 (3 weeks), and 30 days (1 month) (Fig. 2). Since EtOH is an organic solvent, $\mathrm{pH}$ measurement was not performed, as it is measurable. During storage, the bottle of each solution was opened and exposed to air for 1 min a day.
Bactericidal effects of disinfectants under the condition with organic matter

For evaluation of the bactericidal effects of disinfectants, we prepared typical oral bacteria: Streptococcus mutans (JCM 5705, the RIKEN BioResource Center via the National BioResource Project of MEXT, Ibaraki, Japan) and nosocomial infection-related bacteria: Staphylococcus aureus (JCM2151, the RIKEN BioResource Center) and Escherichia. coli (JCM1649T, the RIKEN BioResource Center). These bacteria were cultured in highly nutritious medium, i.e., brain heart infusion (BHI) medium (Beckton, Dickinson, Franklin Lakes, NJ, USA) at $37^{\circ} \mathrm{C}$. This bactericidal test was performed according to ASTM E2315-03 1 Time-Kill test (ASTM E2315-03 Standard Guide for Assessment of Antimicrobial Activity Using a Time-Kill Procedure) (Fig. 2).

Bacteria solution $(500 \mu \mathrm{L}$ BHI medium of OD 0.5 solution, which was subtracted by OD value of BHI medium only) was poured to each disinfectant solution $(9.5 \mathrm{~mL})$, mixed for $10 \mathrm{~s}$, and placed for 0,20 , 
and $50 \mathrm{~s}$ (total treatment time: 10, 30, and $60 \mathrm{~s}$ ). After disinfectant treatment, $0.1 \mathrm{~mL}$ of bacteria solution with each disinfectant was poured to $9.9 \mathrm{~mL}$ of BHI medium, and mixed for $10 \mathrm{~s}$. Further, $20 \mu \mathrm{L}$ of each mixed solution was disseminated on an agar plate (Agar, powder; 01015815 Fujifilm Wako Pure Chemical, Osaka, Japan), cultured at $37^{\circ} \mathrm{C}$ overnight, and the colony number was estimated. In the experimental condition without organic matter, disinfectants were created as $9 \mathrm{~mL}$ of each disinfectant solution with $0.5 \mathrm{~mL}$ of DW (total 9.5 $\mathrm{mL}$ ), and then bacteria solution was added in $0.5 \mathrm{~mL}$ $\mathrm{BHI}$ medium. In the experimental condition with organic matter, disinfectants were created as $9 \mathrm{~mL}$ of each disinfectant solution, and then $0.5 \mathrm{~mL}$ bacteria solution was added with $0.5 \mathrm{~mL}$ of normal rabbit serum (NRS; ICN Biomedicals, Aurora, OH, USA) solution in DW, which indicated that final concentration of NRS was $5 \%$. Final concentration of each disinfectant containing 0.5 $\mathrm{mL}$ of bacteria solution with $0.5 \mathrm{~mL}$ of NRS or DW (total $10 \mathrm{~mL}$ ) was $90 \%$ concentration of added disinfectant (Fig. 2). Control group was added DW instead of disinfectant. Bactericidal effects were assessed as a percentage of colony number of each bacterium with DW treatment (control group).

Rust test of dental steel burs after disinfectant repeatedexposure

Rust of dental carbon steel burs for contra-angle dental handpieces was accessed by visual and microscopic observation under a stereoscopic microscope (SMZ800, Nikon, Tokyo, Japan), the images were captured into the computers by CCD camera (ARTCAM-130MI, Artray, Tokyo, Japan) (Fig. 2). Dental carbon steel burs were immersed in $3 \mathrm{~mL}$ of disinfectants in tightly sealed 3
$\mathrm{mL}$ vials. After dental burs were immersed in $\mathrm{SH}$ and HA for 15 min, they were washed with DW twice; water droplets were blown with air, and air-dried for $30 \mathrm{~min}$. These immersion-air-dry procedures were repeated eight times (total disinfectant immersion time: $2 \mathrm{~h}$ ).

Experimental conditions and data and statistical analysis

All experiments were performed in a laboratory environment maintained at $22-24^{\circ} \mathrm{C}(\mathrm{RT})$ with humidity of 40-50\% under the room luminance of 400-500 lx with UV intensity of below measurable value of the UV meter. Each experiment was repeated 10 times independently, with the maximum and minimum values in each data set being removed before calculation of mean values. Data are presented as the mean \pm standard deviation. The statistical significance of the differences within storage periods and storage conditions in same disinfectants was determined with the Tukey-Kramer test. Statistical significance was set at $p<0.01$. Statistical analysis was performed with EZR (Saitama Medical Center, Jichi Medical University, Saitama, Japan), which is a graphical user interface for $\mathrm{R}$ (The $\mathrm{R}$ Foundation for Statistical Computing; Vienna University of Technology, Vienna, Austria) on a workstation computer (MB-P5300X-WS, Mouse Computer, Tokyo, Japan).

\section{RESULT}

\section{Specifications for bottled commercial HA}

Prior to storage condition-related degradation test, we checked the $\mathrm{pH}$ and $\mathrm{RCC}$ (total $\mathrm{Cl}$ concentration) of five bottled HAs available in the market (Table 1). The measured specifications of two out of the five products did

Table 1 Chlorine concentration and $\mathrm{pH}$ of commercially available bottled hypochlorous acid produced by mixing sodium hypochlorite and $\mathrm{pH}$ regulators

\begin{tabular}{|c|c|c|c|c|c|c|c|}
\hline \multirow{3}{*}{ Product } & \multicolumn{3}{|c|}{ Nominal value /data } & \multicolumn{4}{|c|}{ Measured value } \\
\hline & \multirow{2}{*}{$\mathrm{Cl}(\mathrm{ppm})$} & \multirow{2}{*}{$\mathrm{pH}$} & \multirow{2}{*}{$\mathrm{pH}$ regulator } & \multicolumn{2}{|c|}{$\mathrm{RCC}(\mathrm{ppm})$} & \multicolumn{2}{|c|}{$\mathrm{pH}$} \\
\hline & & & & Value & $\mathrm{AR}$ & Value & Dev \\
\hline $\mathrm{A}$ & no & no & $\mathrm{CH}_{3} \mathrm{COOH}$ & $\begin{array}{c}87.7 \\
(1.87)\end{array}$ & $\mathrm{n} / \mathrm{a}$ & $\begin{array}{c}4.98 \\
(0.08)\end{array}$ & $\mathrm{n} / \mathrm{a}$ \\
\hline $\mathrm{B}$ & 50 & 6.5 & $\mathrm{HCl}$ & $\begin{array}{c}38.2 \\
(1.17)\end{array}$ & $\begin{array}{l}76.4 \% \\
(2.34)\end{array}$ & $\begin{array}{c}6.54 \\
(0.07)\end{array}$ & +0.04 \\
\hline $\mathrm{C}$ & 100 & $5.0-6.5$ & $\mathrm{HCl}$ & $\begin{array}{l}117.7 \\
(1.97)\end{array}$ & $\begin{array}{c}117.7 \% \\
(1.97)\end{array}$ & $\begin{array}{c}3.36 \\
(0.04)\end{array}$ & $-3.14 \sim-1.64$ \\
\hline $\mathrm{D}$ & 100 & 6.5 & $\mathrm{HCl}$ & $\begin{array}{c}6.83 \\
(0.63)\end{array}$ & $\begin{array}{l}6.83 \% \\
(0.63)\end{array}$ & $\begin{array}{c}3.27 \\
(0.03)\end{array}$ & -3.23 \\
\hline $\mathrm{E}$ & 200 & 6.5 & $\mathrm{HCl}$ & $\begin{array}{l}207.8 \\
(4.49)\end{array}$ & $\begin{array}{c}103.9 \% \\
(2.25)\end{array}$ & $\begin{array}{c}6.68 \\
(0.04)\end{array}$ & +0.18 \\
\hline
\end{tabular}

Values are represented as mean and (SD).

$\mathrm{Cl}$; chlorine, RCC; residual chlorine concentration

no; no data in catalog, bottle label and home page of a product, n/a; not available, AR; achievement rate, Dev; deviation

Measurements were averaged over eight measurements taken every 15 min of same bottled HA. 
Table 2 Degradation of disinfectants during various storage conditions

A. Sodium hypochlorite

a) $200 \mathrm{ppm}$

\begin{tabular}{|c|c|c|c|c|c|c|c|c|c|}
\hline \multirow{2}{*}{$\begin{array}{l}\text { Storage } \\
\text { condition }\end{array}$} & \multirow{2}{*}{\multicolumn{2}{|c|}{ Measurement item }} & \multicolumn{7}{|c|}{ Storage period (day) } \\
\hline & & & 0 & 1 & 3 & 7 & 14 & 21 & 30 \\
\hline \multirow{3}{*}{$4 \mathrm{C}$} & \multirow{2}{*}{$\mathrm{RCC}$} & Raw data & $\begin{array}{l}201.2^{\mathrm{a}} \\
(5.21)\end{array}$ & $\begin{array}{c}200.5^{\mathrm{aA}} \\
(3.35)\end{array}$ & $\begin{array}{c}198.1^{\mathrm{aA}} \\
(3.11)\end{array}$ & $\begin{array}{c}197.3^{\mathrm{aA}} \\
(4.55)\end{array}$ & $\begin{array}{c}196.6^{\mathrm{aA}} \\
(3.38)\end{array}$ & $\begin{array}{c}195.8^{\mathrm{aA}} \\
(4.07)\end{array}$ & $\begin{array}{c}195.1^{\mathrm{aA}} \\
(4.11)\end{array}$ \\
\hline & & $\%$ of day 0 & $\begin{array}{l}100.0 \\
(2.59)\end{array}$ & $\begin{array}{c}99.7 \\
(1.67)\end{array}$ & $\begin{array}{c}98.5 \\
(1.55)\end{array}$ & $\begin{array}{c}98.1 \\
(2.26)\end{array}$ & $\begin{array}{c}97.7 \\
(1.68)\end{array}$ & $\begin{array}{c}97.3 \\
(2.02)\end{array}$ & $\begin{array}{c}97.0 \\
(2.04)\end{array}$ \\
\hline & $\mathrm{pH}$ & & $\begin{array}{l}9.58^{\mathrm{a}} \\
(0.14)\end{array}$ & $\begin{array}{c}9.48^{\mathrm{abA}} \\
(0.13)\end{array}$ & $\begin{array}{c}9.42^{\mathrm{abA}} \\
(0.11)\end{array}$ & $\begin{array}{l}9.36^{\mathrm{bcA}} \\
(0.14)\end{array}$ & $\begin{array}{c}9.18^{\mathrm{cdA}} \\
(0.16)\end{array}$ & $\begin{array}{c}8.94^{\mathrm{deA}} \\
(0.18)\end{array}$ & $\begin{array}{l}8.83^{\mathrm{eA}} \\
(0.16)\end{array}$ \\
\hline \multirow{3}{*}{ RT-Shd } & \multirow{2}{*}{$\mathrm{RCC}$} & Raw data & $\uparrow$ & $\begin{array}{c}199.7^{\mathrm{aA}} \\
(3.94)\end{array}$ & $\begin{array}{c}196.6^{\mathrm{abA}} \\
(3.77)\end{array}$ & $\begin{array}{c}193.4^{\mathrm{bcA}} \\
(4.12)\end{array}$ & $\begin{array}{c}191.9^{\mathrm{bcA}} \\
(4.22)\end{array}$ & $\begin{array}{c}191.1^{\mathrm{bcA}} \\
(4.65)\end{array}$ & $\begin{array}{c}188.8^{\mathrm{cB}} \\
(3.56)\end{array}$ \\
\hline & & $\%$ of day 0 & $\uparrow$ & $\begin{array}{c}99.3 \\
(1.96)\end{array}$ & $\begin{array}{c}97.7 \\
(1.87)\end{array}$ & $\begin{array}{c}96.2 \\
(2.05)\end{array}$ & $\begin{array}{c}95.4 \\
(2.10)\end{array}$ & $\begin{array}{c}95.0 \\
(2.31)\end{array}$ & $\begin{array}{c}93.8 \\
(1.77)\end{array}$ \\
\hline & $\mathrm{pH}$ & & $\uparrow$ & $\begin{array}{l}9.56^{\mathrm{aA}} \\
(0.16)\end{array}$ & $\begin{array}{l}9.54^{\mathrm{aA}} \\
(0.14)\end{array}$ & $\begin{array}{l}9.39^{\mathrm{aA}} \\
(0.18)\end{array}$ & $\begin{array}{c}9.09^{\mathrm{bAB}} \\
(0.15)\end{array}$ & $\begin{array}{l}8.73^{\mathrm{cA}} \\
(0.14)\end{array}$ & $\begin{array}{l}8.68^{\mathrm{cA}} \\
(0.13)\end{array}$ \\
\hline \multirow{3}{*}{ RT-LT } & \multirow{2}{*}{$\mathrm{RCC}$} & Raw data & $\uparrow$ & $\begin{array}{c}198.9^{\mathrm{abA}} \\
(4.22)\end{array}$ & $\begin{array}{c}193.4^{\mathrm{bA}} \\
(4.13)\end{array}$ & $\begin{array}{c}157.6^{\mathrm{cB}} \\
(3.98)\end{array}$ & $\begin{array}{c}103.0^{\mathrm{dB}} \\
(3.76)\end{array}$ & $\begin{array}{l}65.4^{\mathrm{eB}} \\
(3.12)\end{array}$ & $\begin{array}{l}43.7^{\mathrm{fC}} \\
(1.38)\end{array}$ \\
\hline & & $\%$ of day0 & $\uparrow$ & $\begin{array}{c}98.9 \\
(2.10)\end{array}$ & $\begin{array}{c}96.1 \\
(2.05)\end{array}$ & $\begin{array}{c}78.3 \\
(1.98)\end{array}$ & $\begin{array}{c}51.2 \\
(1.87)\end{array}$ & $\begin{array}{c}32.5 \\
(1.55)\end{array}$ & $\begin{array}{c}21.7 \\
(0.69)\end{array}$ \\
\hline & $\mathrm{pH}$ & & $\uparrow$ & $\begin{array}{c}9.53^{\mathrm{abA}} \\
(0.13)\end{array}$ & $\begin{array}{c}9.48^{\mathrm{abA}} \\
(0.12)\end{array}$ & $\begin{array}{l}9.32^{\mathrm{bA}} \\
(0.17)\end{array}$ & $\begin{array}{l}8.91^{\mathrm{cB}} \\
(0.16)\end{array}$ & $\begin{array}{l}8.26^{\mathrm{dB}} \\
(0.14)\end{array}$ & $\begin{array}{l}7.73^{\mathrm{eB}} \\
(0.19)\end{array}$ \\
\hline
\end{tabular}

b) $1,000 \mathrm{ppm}$

\begin{tabular}{|c|c|c|c|c|c|c|c|c|c|}
\hline \multirow{2}{*}{$\begin{array}{l}\text { Storage } \\
\text { condition }\end{array}$} & \multirow{2}{*}{\multicolumn{2}{|c|}{ Measurement item }} & \multicolumn{7}{|c|}{ Storage period (day) } \\
\hline & & & 0 & 1 & 3 & 7 & 14 & 21 & 30 \\
\hline \multirow{3}{*}{$4 \mathrm{C}$} & \multirow{2}{*}{$\mathrm{RCC}$} & Raw data & $\begin{array}{c}994.5^{\mathrm{a}} \\
(17.01)\end{array}$ & $\begin{array}{l}992.1^{\mathrm{aA}} \\
(12.94)\end{array}$ & $\begin{array}{c}984.8^{\mathrm{abA}} \\
(14.73)\end{array}$ & $\begin{array}{c}977.8^{\mathrm{abA}} \\
(14.67)\end{array}$ & $\begin{array}{l}968.6^{\mathrm{bA}} \\
(13.41)\end{array}$ & $\begin{array}{l}943.2^{\mathrm{cA}} \\
(10.21)\end{array}$ & $\begin{array}{l}921.5^{\mathrm{dA}} \\
(12.12)\end{array}$ \\
\hline & & $\%$ of day 0 & $\begin{array}{l}100.0 \\
(1.71)\end{array}$ & $\begin{array}{c}99.8 \\
(1.30)\end{array}$ & $\begin{array}{c}99.0 \\
(1.48)\end{array}$ & $\begin{array}{c}98.3 \\
(1.48)\end{array}$ & $\begin{array}{c}97.4 \\
(1.35)\end{array}$ & $\begin{array}{c}94.8 \\
(1.03)\end{array}$ & $\begin{array}{c}92.7 \\
(1.22)\end{array}$ \\
\hline & $\mathrm{pH}$ & & $\begin{array}{l}10.47^{\mathrm{a}} \\
(0.12)\end{array}$ & $\begin{array}{c}10.48^{\mathrm{aA}} \\
(0.14)\end{array}$ & $\begin{array}{c}10.49^{\mathrm{aA}} \\
(0.08)\end{array}$ & $\begin{array}{c}10.50 \mathrm{~A}^{\mathrm{a}} \\
(0.16)\end{array}$ & $\begin{array}{c}10.51^{\mathrm{aA}} \\
(0.18)\end{array}$ & $\begin{array}{c}10.57^{\mathrm{aA}} \\
(0.16)\end{array}$ & $\begin{array}{c}10.62^{\mathrm{aA}} \\
(0.15)\end{array}$ \\
\hline \multirow{3}{*}{ RT-Shd } & \multirow{2}{*}{$\mathrm{RCC}$} & Raw data & $\uparrow$ & $\begin{array}{l}980.7^{\mathrm{aA}} \\
(15.28)\end{array}$ & $\begin{array}{c}973.5^{\mathrm{abA}} \\
(16.33)\end{array}$ & $\begin{array}{c}955.3^{\mathrm{bcB}} \\
(15.32)\end{array}$ & $\begin{array}{l}935.7^{\mathrm{cB}} \\
(15.01)\end{array}$ & $\begin{array}{l}902.3^{\mathrm{dB}} \\
(11.18)\end{array}$ & $\begin{array}{l}868.3^{e B} \\
(13.48)\end{array}$ \\
\hline & & $\%$ of day 0 & $\uparrow$ & $\begin{array}{c}98.6 \\
(1.54)\end{array}$ & $\begin{array}{c}97.9 \\
(1.64)\end{array}$ & $\begin{array}{c}96.1 \\
(1.54)\end{array}$ & $\begin{array}{c}94.1 \\
(1.51)\end{array}$ & $\begin{array}{c}90.7 \\
(1.12)\end{array}$ & $\begin{array}{c}87.3 \\
(1.36)\end{array}$ \\
\hline & $\mathrm{pH}$ & & $\uparrow$ & $\begin{array}{c}10.51^{\mathrm{aA}} \\
(0.17)\end{array}$ & $\begin{array}{c}10.52^{\mathrm{aA}} \\
(0.16)\end{array}$ & $\begin{array}{c}10.53^{\mathrm{aA}} \\
(0.17)\end{array}$ & $\begin{array}{c}10.54^{\mathrm{aA}} \\
(0.15)\end{array}$ & $\begin{array}{c}10.53^{\mathrm{aA}} \\
(0.16)\end{array}$ & $\begin{array}{c}10.52^{\mathrm{aA}} \\
(0.14)\end{array}$ \\
\hline \multirow{3}{*}{ RT-LT } & \multirow{2}{*}{$\mathrm{RCC}$} & Raw data & $\uparrow$ & $\begin{array}{l}971.0^{\mathrm{aA}} \\
(16.23)\end{array}$ & $\begin{array}{l}886.8^{\mathrm{bB}} \\
(11.60)\end{array}$ & $\begin{array}{l}765.5^{\mathrm{cC}} \\
(12.30)\end{array}$ & $\begin{array}{l}452.8^{\mathrm{dC}} \\
(17.54)\end{array}$ & $\begin{array}{l}255.3^{\mathrm{eC}} \\
(10.86)\end{array}$ & $\begin{array}{l}46.7^{\mathrm{fC}} \\
(2.17)\end{array}$ \\
\hline & & $\%$ of day0 & $\uparrow$ & $\begin{array}{c}97.6 \\
(1.63)\end{array}$ & $\begin{array}{c}89.2 \\
(1.17)\end{array}$ & $\begin{array}{c}77.0 \\
(1.24)\end{array}$ & $\begin{array}{c}46.6 \\
(1.76)\end{array}$ & $\begin{array}{c}26.3 \\
(1.09)\end{array}$ & $\begin{array}{c}4.70 \\
(0.22)\end{array}$ \\
\hline & $\mathrm{pH}$ & & $\uparrow$ & $\begin{array}{c}10.52^{\mathrm{aA}} \\
(0.13)\end{array}$ & $\begin{array}{c}10.53^{\mathrm{aA}} \\
(0.11)\end{array}$ & $\begin{array}{c}10.56^{\mathrm{aA}} \\
(0.19)\end{array}$ & $\begin{array}{c}10.48^{\mathrm{aA}} \\
(0.17)\end{array}$ & $\begin{array}{c}10.18^{\mathrm{bB}} \\
(0.17)\end{array}$ & $\begin{array}{l}9.22^{\mathrm{cB}} \\
(0.21)\end{array}$ \\
\hline
\end{tabular}


Table 2 continued

B. Hypochlorous acid

a) Bottled product - mixture of sodium hypochlorite and $\mathrm{HCl}$

\begin{tabular}{|c|c|c|c|c|c|c|c|c|c|}
\hline \multirow{2}{*}{$\begin{array}{l}\text { Storage } \\
\text { condition }\end{array}$} & \multirow{2}{*}{\multicolumn{2}{|c|}{ Measurement item }} & \multicolumn{7}{|c|}{ Storage period (day) } \\
\hline & & & 0 & 1 & 3 & 7 & 14 & 21 & 30 \\
\hline \multirow{3}{*}{$4 \mathrm{C}$} & \multirow{2}{*}{$\mathrm{RCC}$} & Raw data & $\begin{array}{l}207.8^{\mathrm{a}} \\
(4.49)\end{array}$ & $\begin{array}{c}203.8^{\mathrm{abA}} \\
(7.21)\end{array}$ & $\begin{array}{c}198.9^{\mathrm{bcA}} \\
(6.92)\end{array}$ & $\begin{array}{c}193.1^{\mathrm{cdA}} \\
(6.23)\end{array}$ & $\begin{array}{c}186.7^{\mathrm{dA}} \\
(6.66)\end{array}$ & $\begin{array}{c}184.3^{\mathrm{dA}} \\
(6.98)\end{array}$ & $\begin{array}{c}183.7^{\mathrm{dA}} \\
(7.41)\end{array}$ \\
\hline & & $\%$ of day0 & $\begin{array}{l}100.0 \\
(2.16)\end{array}$ & $\begin{array}{c}98.1 \\
(3.47)\end{array}$ & $\begin{array}{c}95.7 \\
(3.33)\end{array}$ & $\begin{array}{c}92.9 \\
(3.00)\end{array}$ & $\begin{array}{c}89.8 \\
(3.21)\end{array}$ & $\begin{array}{c}88.7 \\
(3.36)\end{array}$ & $\begin{array}{c}88.4 \\
(3.57)\end{array}$ \\
\hline & $\mathrm{pH}$ & & $\begin{array}{l}6.68^{\mathrm{a}} \\
(0.14)\end{array}$ & $\begin{array}{l}6.64^{\mathrm{aA}} \\
(0.15)\end{array}$ & $\begin{array}{l}6.62^{\mathrm{aA}} \\
(0.15)\end{array}$ & $\begin{array}{l}6.59^{\mathrm{aA}} \\
(0.14)\end{array}$ & $\begin{array}{l}6.57^{\mathrm{aA}} \\
(0.21)\end{array}$ & $\begin{array}{l}6.55^{\mathrm{aA}} \\
(0.17)\end{array}$ & $\begin{array}{l}6.52^{\mathrm{aA}} \\
(0.16)\end{array}$ \\
\hline \multirow{3}{*}{ RT-Shd } & \multirow{2}{*}{$\mathrm{RCC}$} & Raw data & $\uparrow$ & $\begin{array}{c}200.3^{\mathrm{abA}} \\
(6.88)\end{array}$ & $\begin{array}{c}191.3^{\mathrm{bcAB}} \\
(6.51)\end{array}$ & $\begin{array}{c}184.1^{\mathrm{cA}} \\
(7.01)\end{array}$ & $\begin{array}{c}172.8^{\mathrm{dB}} \\
(6.87)\end{array}$ & $\begin{array}{c}169.4^{\mathrm{dB}} \\
(7.41)\end{array}$ & $\begin{array}{c}164.3^{\mathrm{dB}} \\
(6.38)\end{array}$ \\
\hline & & $\%$ of day0 & $\uparrow$ & $\begin{array}{c}96.4 \\
(3.31)\end{array}$ & $\begin{array}{c}92.1 \\
(3.11)\end{array}$ & $\begin{array}{c}88.6 \\
(3.37)\end{array}$ & $\begin{array}{c}83.2 \\
(3.31)\end{array}$ & $\begin{array}{c}81.5 \\
(3.57)\end{array}$ & $\begin{array}{c}79.1 \\
(3.07)\end{array}$ \\
\hline & $\mathrm{pH}$ & & $\uparrow$ & $\begin{array}{c}6.57^{\mathrm{abAB}} \\
(0.14)\end{array}$ & $\begin{array}{c}6.53^{\mathrm{abAB}} \\
(0.15)\end{array}$ & $\begin{array}{c}6.47^{\mathrm{abAB}} \\
(0.16)\end{array}$ & $\begin{array}{l}6.43^{\mathrm{bA}} \\
(0.15)\end{array}$ & $\begin{array}{l}6.41^{\mathrm{bA}} \\
(0.12)\end{array}$ & $\begin{array}{l}6.38^{\mathrm{bA}} \\
(0.09)\end{array}$ \\
\hline \multirow{3}{*}{ RT-LT } & \multirow{2}{*}{$\mathrm{RCC}$} & Raw data & $\uparrow$ & $\begin{array}{c}196.2^{\mathrm{aA}} \\
(7.38)\end{array}$ & $\begin{array}{c}181.8^{\mathrm{bB}} \\
(7.98)\end{array}$ & $\begin{array}{c}166.2^{\mathrm{cB}} \\
(6.98)\end{array}$ & $\begin{array}{c}138.5^{\mathrm{dC}} \\
(7.21)\end{array}$ & $\begin{array}{c}104.3^{\mathrm{eC}} \\
(7.33)\end{array}$ & $\begin{array}{l}51.3^{\mathrm{fC}} \\
(6.65)\end{array}$ \\
\hline & & $\%$ of day 0 & $\uparrow$ & $\begin{array}{c}94.4 \\
(3.55)\end{array}$ & $\begin{array}{c}87.5 \\
(3.84)\end{array}$ & $\begin{array}{c}80.0 \\
(3.36)\end{array}$ & $\begin{array}{c}66.7 \\
(3.47)\end{array}$ & $\begin{array}{c}50.2 \\
(3.53)\end{array}$ & $\begin{array}{c}24.7 \\
(3.20)\end{array}$ \\
\hline & $\mathrm{pH}$ & & $\uparrow$ & $\begin{array}{l}6.39^{\mathrm{bB}} \\
(0.13)\end{array}$ & $\begin{array}{l}6.38^{\mathrm{bB}} \\
(0.15)\end{array}$ & $\begin{array}{l}6.27^{\mathrm{bB}} \\
(0.19)\end{array}$ & $\begin{array}{l}5.86^{\mathrm{cB}} \\
(0.14)\end{array}$ & $\begin{array}{l}4.83^{\mathrm{dB}} \\
(0.13)\end{array}$ & $\begin{array}{l}3.15^{\mathrm{eB}} \\
(0.11)\end{array}$ \\
\hline
\end{tabular}

b) Electrolysis type at on-site generation

\begin{tabular}{|c|c|c|c|c|c|c|c|c|c|}
\hline \multirow{2}{*}{$\begin{array}{l}\text { Storage } \\
\text { condition }\end{array}$} & \multirow{2}{*}{\multicolumn{2}{|c|}{ Measurement item }} & \multicolumn{7}{|c|}{ Storage period (day) } \\
\hline & & & 0 & 1 & 3 & 7 & 14 & 21 & 30 \\
\hline \multirow{3}{*}{$4 \mathrm{C}$} & \multirow{2}{*}{$\mathrm{RCC}$} & Raw data & $\begin{array}{l}54.7^{\mathrm{a}} \\
(1.51)\end{array}$ & $\begin{array}{c}54.0^{\mathrm{abA}} \\
(1.41)\end{array}$ & $\begin{array}{l}52.7^{\mathrm{bA}} \\
(0.82)\end{array}$ & $\begin{array}{l}49.5^{\mathrm{cA}} \\
(1.76)\end{array}$ & $\begin{array}{l}43.3^{\mathrm{dA}} \\
(2.27)\end{array}$ & $\begin{array}{l}39.8^{\mathrm{eA}} \\
(2.12)\end{array}$ & $\begin{array}{l}36.5^{\mathrm{fA}} \\
(1.38)\end{array}$ \\
\hline & & $\%$ of day0 & $\begin{array}{l}100.0 \\
(2.76)\end{array}$ & $\begin{array}{c}98.7 \\
(2.58)\end{array}$ & $\begin{array}{c}96.3 \\
(1.50)\end{array}$ & $\begin{array}{c}90.5 \\
(3.22)\end{array}$ & $\begin{array}{c}79.2 \\
(4.15)\end{array}$ & $\begin{array}{c}72.8 \\
(3.88)\end{array}$ & $\begin{array}{c}66.7 \\
(2.52)\end{array}$ \\
\hline & $\mathrm{pH}$ & & $\begin{array}{l}3.31^{\mathrm{a}} \\
(0.16)\end{array}$ & $\begin{array}{l}3.31^{\mathrm{aA}} \\
(0.16)\end{array}$ & $\begin{array}{l}3.30^{\mathrm{aA}} \\
(0.15)\end{array}$ & $\begin{array}{l}3.24^{\mathrm{aA}} \\
(0.17)\end{array}$ & $\begin{array}{l}3.22^{\mathrm{aA}} \\
(0.16)\end{array}$ & $\begin{array}{l}3.21^{\mathrm{aA}} \\
(0.09)\end{array}$ & $\begin{array}{l}3.19^{\mathrm{aA}} \\
(0.14)\end{array}$ \\
\hline \multirow{3}{*}{ RT-Shd } & \multirow{2}{*}{$\mathrm{RCC}$} & Raw data & $\uparrow$ & $\begin{array}{l}51.3^{\mathrm{bB}} \\
(1.21)\end{array}$ & $\begin{array}{l}45.3^{\mathrm{cB}} \\
(2.16)\end{array}$ & $\begin{array}{l}39.2^{\mathrm{dB}} \\
(0.74)\end{array}$ & $\begin{array}{l}32.2^{\mathrm{eB}} \\
(1.86)\end{array}$ & $\begin{array}{l}27.8^{\mathrm{fB}} \\
(1.65)\end{array}$ & $\begin{array}{l}22.0^{\mathrm{gB}} \\
(1.79)\end{array}$ \\
\hline & & $\%$ of day0 & $\uparrow$ & $\begin{array}{c}93.8 \\
(2.21)\end{array}$ & $\begin{array}{c}82.8 \\
(3.95)\end{array}$ & $\begin{array}{c}71.7 \\
(1.35)\end{array}$ & $\begin{array}{c}58.9 \\
(3.40)\end{array}$ & $\begin{array}{c}50.8 \\
(3.02)\end{array}$ & $\begin{array}{c}40.2 \\
(3.27)\end{array}$ \\
\hline & $\mathrm{pH}$ & & $\uparrow$ & $\begin{array}{l}3.31^{\mathrm{aA}} \\
(0.13)\end{array}$ & $\begin{array}{l}3.26^{\mathrm{aA}} \\
(0.13)\end{array}$ & $\begin{array}{l}3.22^{\mathrm{aA}} \\
(0.15)\end{array}$ & $\begin{array}{l}3.14^{\mathrm{aA}} \\
(0.14)\end{array}$ & $\begin{array}{c}3.13^{\mathrm{aAB}} \\
(0.11)\end{array}$ & $\begin{array}{c}3.10^{\mathrm{aAB}} \\
(0.15)\end{array}$ \\
\hline \multirow{3}{*}{ RT-LT } & \multirow{2}{*}{$\mathrm{RCC}$} & Raw data & $\uparrow$ & $\begin{array}{l}47.7^{\mathrm{bC}} \\
(1.03)\end{array}$ & $\begin{array}{l}40.8^{\mathrm{cC}} \\
(2.16)\end{array}$ & $\begin{array}{l}27.6^{\mathrm{dC}} \\
(1.26)\end{array}$ & $\begin{array}{l}17.5^{\mathrm{eC}} \\
(1.98)\end{array}$ & $\begin{array}{c}9.3^{\mathrm{fC}} \\
(0.89)\end{array}$ & $\begin{array}{c}1.1^{\mathrm{gC}} \\
(0.16)\end{array}$ \\
\hline & & $\%$ of day0 & $\uparrow$ & $\begin{array}{c}87.2 \\
(1.88)\end{array}$ & $\begin{array}{c}74.6 \\
(3.95)\end{array}$ & $\begin{array}{c}50.5 \\
(2.30)\end{array}$ & $\begin{array}{c}32.0 \\
(3.62)\end{array}$ & $\begin{array}{c}17.0 \\
(0.43)\end{array}$ & $\begin{array}{c}2.0 \\
(0.29)\end{array}$ \\
\hline & $\mathrm{pH}$ & & $\uparrow$ & $\begin{array}{l}3.30^{\mathrm{aA}} \\
(0.15)\end{array}$ & $\begin{array}{c}3.21^{\mathrm{abA}} \\
(0.13)\end{array}$ & $\begin{array}{c}3.12^{\mathrm{abcA}} \\
(0.14)\end{array}$ & $\begin{array}{c}3.01^{\text {bcA }} \\
(0.16)\end{array}$ & $\begin{array}{l}2.95^{\mathrm{cB}} \\
(0.18)\end{array}$ & $\begin{array}{l}2.92^{\mathrm{cB}} \\
(0.16)\end{array}$ \\
\hline
\end{tabular}


Table 2 continued

c) $\mathrm{CO}_{2}$ mixture type at on-site generation

(1) $120 \mathrm{ppm}$ by a product generator

\begin{tabular}{|c|c|c|c|c|c|c|c|c|c|}
\hline \multirow{2}{*}{$\begin{array}{l}\text { Storage } \\
\text { condition }\end{array}$} & \multirow{2}{*}{\multicolumn{2}{|c|}{ Measurement item }} & \multicolumn{7}{|c|}{ Storage period (day) } \\
\hline & & & 0 & 1 & 3 & 7 & 14 & 21 & 30 \\
\hline \multirow{3}{*}{$4 \mathrm{C}$} & \multirow{2}{*}{$\mathrm{RCC}$} & Raw data & $\begin{array}{l}127.6^{\mathrm{a}} \\
(3.49)\end{array}$ & $\begin{array}{c}126.2^{\mathrm{aA}} \\
(2.30)\end{array}$ & $\begin{array}{c}121.2^{\mathrm{bA}} \\
(2.05)\end{array}$ & $\begin{array}{c}116.9^{\mathrm{cA}} \\
(3.05)\end{array}$ & $\begin{array}{c}113.2^{\mathrm{cdA}} \\
(2.16)\end{array}$ & $\begin{array}{c}109.6^{\mathrm{dA}} \\
(2.77)\end{array}$ & $\begin{array}{c}105.5^{\mathrm{eA}} \\
(2.65)\end{array}$ \\
\hline & & $\%$ of day0 & $\begin{array}{l}100.0 \\
(2.74)\end{array}$ & $\begin{array}{c}98.9 \\
(1.80)\end{array}$ & $\begin{array}{c}95.0 \\
(1.61)\end{array}$ & $\begin{array}{c}91.6 \\
(2.39)\end{array}$ & $\begin{array}{c}88.7 \\
(1.69)\end{array}$ & $\begin{array}{l}85.9 \\
(2.17)\end{array}$ & $\begin{array}{l}82.6 \\
(2.08)\end{array}$ \\
\hline & $\mathrm{pH}$ & & $\begin{array}{l}6.50^{\mathrm{a}} \\
(0.15)\end{array}$ & $\begin{array}{l}6.50^{\mathrm{aA}} \\
(0.14)\end{array}$ & $\begin{array}{l}6.52^{\mathrm{aA}} \\
(0.13)\end{array}$ & $\begin{array}{l}6.55^{\mathrm{aA}} \\
(0.13)\end{array}$ & $\begin{array}{l}6.57^{\mathrm{aA}} \\
(0.09)\end{array}$ & $\begin{array}{l}6.56^{\mathrm{aA}} \\
(0.16)\end{array}$ & $\begin{array}{l}6.56^{\mathrm{aA}} \\
(0.15)\end{array}$ \\
\hline \multirow{3}{*}{ RT-Shd } & \multirow{2}{*}{$\mathrm{RCC}$} & Raw data & $\uparrow$ & $\begin{array}{c}124.8^{\mathrm{aA}} \\
(2.93)\end{array}$ & $\begin{array}{c}117.0^{\mathrm{bB}} \\
(2.61)\end{array}$ & $\begin{array}{c}107.7^{\mathrm{cB}} \\
(1.86)\end{array}$ & $\begin{array}{l}96.5^{\mathrm{dB}} \\
(2.67)\end{array}$ & $\begin{array}{l}87.7^{\mathrm{eB}} \\
(3.10)\end{array}$ & $\begin{array}{l}80.3^{\mathrm{fB}} \\
(2.48)\end{array}$ \\
\hline & & $\%$ of day0 & $\uparrow$ & $\begin{array}{c}97.8 \\
(2.30)\end{array}$ & $\begin{array}{c}91.7 \\
(2.05)\end{array}$ & $\begin{array}{c}84.4 \\
(1.46)\end{array}$ & $\begin{array}{c}75.6 \\
(2.09)\end{array}$ & $\begin{array}{c}68.7 \\
(2.43)\end{array}$ & $\begin{array}{c}62.9 \\
(1.94)\end{array}$ \\
\hline & $\mathrm{pH}$ & & $\uparrow$ & $\begin{array}{l}6.51^{\mathrm{aA}} \\
(0.12)\end{array}$ & $\begin{array}{c}6.53^{\mathrm{abA}} \\
(0.14)\end{array}$ & $\begin{array}{c}6.59^{\mathrm{abA}} \\
(0.12)\end{array}$ & $\begin{array}{c}6.68^{\mathrm{abA}} \\
(0.16)\end{array}$ & $\begin{array}{c}6.79^{\mathrm{bcB}} \\
(0.11)\end{array}$ & $\begin{array}{l}6.94^{\mathrm{cB}} \\
(0.14)\end{array}$ \\
\hline \multirow{3}{*}{ RT-LT } & \multirow{2}{*}{$\mathrm{RCC}$} & Raw data & $\uparrow$ & $\begin{array}{c}116.5^{\mathrm{bB}} \\
(3.08)\end{array}$ & $\begin{array}{c}107.3^{\mathrm{cC}} \\
(3.25)\end{array}$ & $\begin{array}{l}88.5^{\mathrm{dC}} \\
(3.37)\end{array}$ & $\begin{array}{l}62.1^{\mathrm{eC}} \\
(3.82)\end{array}$ & $\begin{array}{l}36.4^{\mathrm{fC}} \\
(3.21)\end{array}$ & $\begin{array}{l}11.2^{\mathrm{gC}} \\
(1.97)\end{array}$ \\
\hline & & $\%$ of day 0 & $\uparrow$ & $\begin{array}{c}91.3 \\
(2.41)\end{array}$ & $\begin{array}{c}84.1 \\
(2.55)\end{array}$ & $\begin{array}{c}69.4 \\
(2.64)\end{array}$ & $\begin{array}{c}48.7 \\
(2.99)\end{array}$ & $\begin{array}{c}28.5 \\
(2.52)\end{array}$ & $\begin{array}{c}8.8 \\
(1.54)\end{array}$ \\
\hline & $\mathrm{pH}$ & & $\uparrow$ & $\begin{array}{l}6.53^{\mathrm{aA}} \\
(0.12)\end{array}$ & $\begin{array}{l}6.59^{\mathrm{aA}} \\
(0.17)\end{array}$ & $\begin{array}{l}6.65^{\mathrm{aA}} \\
(0.14)\end{array}$ & $\begin{array}{l}6.72^{\mathrm{aA}} \\
(0.15)\end{array}$ & $\begin{array}{c}6.68^{\mathrm{aAB}} \\
(0.19)\end{array}$ & $\begin{array}{l}6.63^{\mathrm{aA}} \\
(0.14)\end{array}$ \\
\hline
\end{tabular}

(2) 200 ppm by a prototype generator

\begin{tabular}{|c|c|c|c|c|c|c|c|c|c|}
\hline \multirow{2}{*}{$\begin{array}{l}\text { Storage } \\
\text { condition }\end{array}$} & \multirow{2}{*}{\multicolumn{2}{|c|}{ Measurement item }} & \multicolumn{7}{|c|}{ Storage period (day) } \\
\hline & & & 0 & 1 & 3 & 7 & 14 & 21 & 30 \\
\hline \multirow{3}{*}{$4 \mathrm{C}$} & \multirow{2}{*}{$\mathrm{RCC}$} & Raw data & $\begin{array}{l}240.8^{\mathrm{a}} \\
(6.43)\end{array}$ & $\begin{array}{c}237.2^{\mathrm{a}} \\
(3.52)\end{array}$ & $\begin{array}{l}227.8^{b} \\
(3.44)\end{array}$ & $\begin{array}{l}217.7^{\mathrm{c}} \\
(4.50)\end{array}$ & $\begin{array}{l}208.1^{\mathrm{d}} \\
(6.55)\end{array}$ & $\begin{array}{l}197.7^{\mathrm{e}} \\
(5.63)\end{array}$ & $\begin{array}{l}189.8^{f} \\
(4.09)\end{array}$ \\
\hline & & $\%$ of day 0 & $\begin{array}{l}100.0 \\
(2.67)\end{array}$ & $\begin{array}{c}98.5 \\
(1.46)\end{array}$ & $\begin{array}{c}94.6 \\
(1.43)\end{array}$ & $\begin{array}{c}90.4 \\
(1.87)\end{array}$ & $\begin{array}{c}86.4 \\
(2.72)\end{array}$ & $\begin{array}{c}82.1 \\
(2.34)\end{array}$ & $\begin{array}{c}78.8 \\
(1.70)\end{array}$ \\
\hline & $\mathrm{pH}$ & & $\begin{array}{l}6.21^{\mathrm{a}} \\
(0.16)\end{array}$ & $\begin{array}{l}6.22^{\mathrm{aA}} \\
(0.09)\end{array}$ & $\begin{array}{l}6.23^{\mathrm{aA}} \\
(0.17)\end{array}$ & $\begin{array}{l}6.25^{\mathrm{aA}} \\
(0.11)\end{array}$ & $\begin{array}{l}6.31^{\mathrm{aA}} \\
(0.13)\end{array}$ & $\begin{array}{l}6.34^{\mathrm{aA}} \\
(0.13)\end{array}$ & $\begin{array}{l}6.33^{\mathrm{aA}} \\
(0.09)\end{array}$ \\
\hline \multirow{3}{*}{ RT-Shd } & \multirow{2}{*}{$\mathrm{RCC}$} & Raw data & $\uparrow$ & $\begin{array}{l}221.2^{\mathrm{b}} \\
(5.06)\end{array}$ & $\begin{array}{l}212.7^{\mathrm{c}} \\
(4.10)\end{array}$ & $\begin{array}{l}197.3^{\mathrm{d}} \\
(5.61)\end{array}$ & $\begin{array}{l}169.8^{\mathrm{e}} \\
(5.13)\end{array}$ & $\begin{array}{l}147.3^{f} \\
(6.58)\end{array}$ & $\begin{array}{l}124.5^{\mathrm{g}} \\
(4.49)\end{array}$ \\
\hline & & $\%$ of day 0 & $\uparrow$ & $\begin{array}{c}91.9 \\
(2.10)\end{array}$ & $\begin{array}{c}88.3 \\
(1.70)\end{array}$ & $\begin{array}{c}81.9 \\
(2.33)\end{array}$ & $\begin{array}{c}70.5 \\
(2.13)\end{array}$ & $\begin{array}{c}61.2 \\
(2.73)\end{array}$ & $\begin{array}{c}51.7 \\
(1.86)\end{array}$ \\
\hline & $\mathrm{pH}$ & & $\uparrow$ & $\begin{array}{l}6.23^{\mathrm{aA}} \\
(0.15)\end{array}$ & $\begin{array}{l}6.24^{\mathrm{aA}} \\
(0.14)\end{array}$ & $\begin{array}{l}6.28^{\mathrm{aA}} \\
(0.16)\end{array}$ & $\begin{array}{c}6.37^{\mathrm{abAB}} \\
(0.15)\end{array}$ & $\begin{array}{c}6.53^{\mathrm{bcA}} \\
(0.13)\end{array}$ & $\begin{array}{l}6.69^{\mathrm{cB}} \\
(0.17)\end{array}$ \\
\hline \multirow{3}{*}{ RT-LT } & \multirow{2}{*}{$\mathrm{RCC}$} & Raw data & $\uparrow$ & $\begin{array}{l}210.5^{\mathrm{b}} \\
(4.85)\end{array}$ & $\begin{array}{l}198.2^{\mathrm{c}} \\
(5.64)\end{array}$ & $\begin{array}{l}165.7^{\mathrm{d}} \\
(4.88)\end{array}$ & $\begin{array}{l}111.2^{\mathrm{e}} \\
(4.36)\end{array}$ & $\begin{array}{c}48.9^{f} \\
(4.05)\end{array}$ & $\begin{array}{c}5.4^{\mathrm{g}} \\
(1.38)\end{array}$ \\
\hline & & $\%$ of day 0 & $\uparrow$ & $\begin{array}{c}87.4 \\
(2.01)\end{array}$ & $\begin{array}{c}82.3 \\
(2.34)\end{array}$ & $\begin{array}{c}68.8 \\
(2.03)\end{array}$ & $\begin{array}{c}46.2 \\
(1.81)\end{array}$ & $\begin{array}{c}20.3 \\
(1.68)\end{array}$ & $\begin{array}{c}2.2 \\
(0.57)\end{array}$ \\
\hline & $\mathrm{pH}$ & & $\uparrow$ & $\begin{array}{l}6.25^{\mathrm{aA}} \\
(0.14)\end{array}$ & $\begin{array}{c}6.31^{\mathrm{abA}} \\
(0.16)\end{array}$ & $\begin{array}{c}6.35^{\mathrm{abA}} \\
(0.17)\end{array}$ & $\begin{array}{c}6.43^{\text {abB }} \\
(0.15)\end{array}$ & $\begin{array}{l}6.47^{\mathrm{bA}} \\
(0.11)\end{array}$ & $\begin{array}{l}6.46^{\mathrm{bA}} \\
(0.12)\end{array}$ \\
\hline
\end{tabular}


Table 2 continued

C. Disinfectant alcohol (80\% ethanol solution)

\begin{tabular}{|c|c|c|c|c|c|c|c|c|c|}
\hline \multirow{2}{*}{$\begin{array}{l}\text { Storage } \\
\text { condition }\end{array}$} & \multirow{2}{*}{\multicolumn{2}{|c|}{ Measurement item }} & \multicolumn{7}{|c|}{ Storage period (day) } \\
\hline & & & 0 & 1 & 3 & 7 & 14 & 21 & 30 \\
\hline \multirow{2}{*}{$4 \mathrm{C}$} & \multirow{2}{*}{$\mathrm{EtOH}$} & Raw data & $\begin{array}{l}80.9^{\mathrm{a}} \\
(1.06)\end{array}$ & $\begin{array}{c}80.2^{\mathrm{abA}} \\
(1.26)\end{array}$ & $\begin{array}{l}79.8^{\mathrm{abA}} \\
(0.92)\end{array}$ & $\begin{array}{c}79.4^{\mathrm{abcA}} \\
(0.99)\end{array}$ & $\begin{array}{l}79.1^{\mathrm{bcA}} \\
(1.02)\end{array}$ & $\begin{array}{l}78.6^{\mathrm{bcA}} \\
(0.89)\end{array}$ & $\begin{array}{l}78.1^{\mathrm{cA}} \\
(1.09)\end{array}$ \\
\hline & & $\%$ of day0 & $\begin{array}{l}100.0 \\
(1.31)\end{array}$ & $\begin{array}{c}99.1 \\
(1.56)\end{array}$ & $\begin{array}{c}98.6 \\
(1.14)\end{array}$ & $\begin{array}{c}98.1 \\
(1.22)\end{array}$ & $\begin{array}{c}97.8 \\
(1.26)\end{array}$ & $\begin{array}{c}97.2 \\
(1.10)\end{array}$ & $\begin{array}{c}96.5 \\
(1.35)\end{array}$ \\
\hline \multirow{2}{*}{ RT-Shd } & \multirow{2}{*}{$\mathrm{EtOH}$} & Raw data & $\uparrow$ & $\begin{array}{l}79.6^{\mathrm{abA}} \\
(1.16)\end{array}$ & $\begin{array}{l}79.2^{\mathrm{bA}} \\
(1.08)\end{array}$ & $\begin{array}{l}78.6^{\mathrm{bcA}} \\
(1.11)\end{array}$ & $\begin{array}{l}78.3^{\mathrm{bcA}} \\
(0.84)\end{array}$ & $\begin{array}{l}77.1^{\mathrm{cB}} \\
(0.96)\end{array}$ & $\begin{array}{l}75.4^{\mathrm{dB}} \\
(0.89)\end{array}$ \\
\hline & & $\%$ of day0 & $\uparrow$ & $\begin{array}{c}98.4 \\
(1.43)\end{array}$ & $\begin{array}{c}97.9 \\
(1.33)\end{array}$ & $\begin{array}{c}97.2 \\
(1.37)\end{array}$ & $\begin{array}{c}96.8 \\
(1.04)\end{array}$ & $\begin{array}{c}95.3 \\
(1.19)\end{array}$ & $\begin{array}{c}93.2 \\
(1.10)\end{array}$ \\
\hline \multirow{2}{*}{ RT-LT } & \multirow{2}{*}{$\mathrm{EtOH}$} & Raw data & $\uparrow$ & $\begin{array}{l}78.7^{\mathrm{bA}} \\
(1.04)\end{array}$ & $\begin{array}{l}77.5^{\mathrm{bcB}} \\
(1.25)\end{array}$ & $\begin{array}{l}76.7^{\mathrm{cB}} \\
(1.17)\end{array}$ & $\begin{array}{l}75.9^{\mathrm{cB}} \\
(0.91)\end{array}$ & $\begin{array}{l}73.8^{\mathrm{dC}} \\
(0.95)\end{array}$ & $\begin{array}{l}70.2^{\mathrm{eC}} \\
(0.99)\end{array}$ \\
\hline & & $\%$ of day0 & $\uparrow$ & $\begin{array}{c}97.3 \\
(1.29)\end{array}$ & $\begin{array}{c}95.8 \\
(1.55)\end{array}$ & $\begin{array}{c}94.8 \\
(1.45)\end{array}$ & $\begin{array}{c}93.8 \\
(1.12)\end{array}$ & $\begin{array}{c}91.2 \\
(1.17)\end{array}$ & $\begin{array}{c}86.8 \\
(1.22)\end{array}$ \\
\hline
\end{tabular}

$n=8$ for each experimental condition.

Values are represented as mean and (SD). HA; hypochlorous acid, RCC; residual chlorine concentration, EtOH; ethanol, 4C; $4^{\circ} \mathrm{C}$ with shading in a refrigerator, RT; room temperature, Shd; shading, LT; lighting.

Temperature:22.5 $\pm 0.83^{\circ} \mathrm{C}$, illumination(fluorescent lamp lighting): $2022.5 \pm 84.01 \mathrm{~lx}$, and UV intensity: $10.7 \pm 1.21 \mu \mathrm{W} / \mathrm{cm}^{2}$.

Different superscript small and capital letters denote statistically significant differences $(p<0.01)$

within the storage periods containing day 0 under the same storage condition, and within the storage conditions in the same storage periods, respectively.

not meet the product's published specifications (product $\mathrm{B}$ and $\mathrm{D}$ in Table 1). Product A had no specifications listed and the RCC of product C was almost $20 \%$ over the listed specifications. Only product E satisfied the nominal value that was shipped in a refrigerated state immediately after generation.

From these results, we investigated HA generated at laboratory using two kinds of generators: EL and $\mathrm{CO}_{2}$ types, in subsequent experiments with bottled product $\mathrm{E}$ (mixture of $\mathrm{SH}$ and $\mathrm{HCl}), \mathrm{SH}$, and $\mathrm{DA}(80 \% \mathrm{EtOH}$ solution).

\section{Storage condition-related degradation test of disinfectants}

To examine the degradation of the solution's potency during storage, $\mathrm{RCC}$ and $\mathrm{pH}$ in $\mathrm{SH}$ and $\mathrm{HA}$, and $\mathrm{EtOH}$ concentration in DA were measured over time (Tables 2A-C). We estimated free $\mathrm{Cl}$ concentration of each solution at the same time of RCC estimation, and these values were almost similar to RCC (data not shown). The RCC and $\mathrm{pH}$ of each solution was measured after storage at RT under LT of fluorescent lamps for $24 \mathrm{~h}$ per day, RT-storage with Shd, and storage at $4^{\circ} \mathrm{C}$ in a refrigerator with shd (4C) for 0 (immediate after generation), 1, 3, 7 (1 week), 14 (2 weeks), 21 (3 weeks), and 30 days (1 month).

As for the SH solution (Tables 2A a), b), and 3), RCC did not decrease significantly in 30 days for both the $4 \mathrm{C}$ and RT-Shd-storage solutions. In contrast, RCC of the specimens exposed to LT at RT decreased linearly with time, and decreased by half in 14 days. On day 30, RCC decreased by approximately $95 \%$ in 1,000 ppm and $80 \%$ in $200 \mathrm{ppm}$. The decrease in $\mathrm{pH}$ was accompanied with the decrease in RCC.

The changes in RCC and $\mathrm{pH}$ were also studied for three types of four HAs: a bottled HA, an EL type HA generated at on-site, and two concentrations of $\mathrm{CO}_{2} \mathrm{HAs}$ generated at on-site (Tables $2 \mathrm{~B}$ and 3 ). For bottled HA produced by mixing $\mathrm{SH}$ and $\mathrm{HCl}, \mathrm{RCC}$ in Shd groups (4C and RT-Shd) decreased slowly with constant $\mathrm{pH}$ over time. In contrast, RCC of the specimens exposed to LT at $\mathrm{RT}$ decreased linearly with time, and decrease in $\mathrm{pH}$ was accompanied with the decrease in RCC (Tables 2B a) and $3)$. These changes were similar to those of $\mathrm{SH}$ solution. In contrast, the RCC of EL type HA decreased rapidly even in $4 \mathrm{C}$ storage. Furthermore, RCC decreased equally with time by the effects of temperature and lighting (Tables $2 \mathrm{~B} \mathrm{~b}$ ) and 3 ). RCC seemed to drop rapidly during the first week and then linearly. It decreased approximately twothird of $\mathrm{Cl}$ concentration in 30 days for the $4 \mathrm{C}$ ones, onethird at RT-Shd, and almost zero for the ones exposed to $\mathrm{LT}$ at RT. There was no significant change in $\mathrm{pH}$ in the EL type HA. The $\mathrm{CO}_{2}$ type HAs generated from both the generators in the market (nominal value: $120 \mathrm{ppm}$, measured RCC: $127.6 \mathrm{ppm}$ ) and prototype (measured RCC: $240.8 \mathrm{ppm}$ ) showed essentially the same decrease pattern in RCC and pH (Tables 2B c) (1) (2) and 3). The decrease in RCC by temperature was more pronounced at higher concentrations; however, the effect of lighting was greater than that of temperature. In the $\mathrm{CO}_{2}$ type $\mathrm{HA}$, unlike the $\mathrm{SH}$ and $2 \mathrm{Mx}$ type bottled $\mathrm{HA}$, the $\mathrm{pH}$ increased with degradation. The decrease in RCC over 
time was linear, decreasing by approximately $10 \%$ and $5 \%$ in the $4 \mathrm{C}$ samples and $20 \%$ and $10 \%$ in the RT-Shd samples of $120 \mathrm{ppm}$ and $200 \mathrm{ppm}$ after 30 day-storage, respectively. RCC of $120 \mathrm{ppm}$ and $200 \mathrm{ppm}$ HA exposed to lighting at RT decreased linearly to $1 / 10$ and $1 / 50$ in
30 days.

For DA, i.e., 80\% EtOH (Tables $2 \mathrm{C}$ and 3), the concentration of the $4 \mathrm{C}$-EtOH was almost unchanged in 30 days; however, the concentration decreased after 3 weeks and decreased by approximately $7 \%$ after 30 day-

Table 3 Comparison of residual chlorine concentration changes of different method generated hypochlorous acid under various storage conditions

A. Storage at $4^{\circ} \mathrm{C}$ with shading in a refrigerator

\begin{tabular}{|c|c|c|c|c|c|c|c|c|}
\hline \multirow{2}{*}{\multicolumn{2}{|c|}{$\%$ of RCC at day 0}} & \multicolumn{7}{|c|}{ Storage periods (day) } \\
\hline & & 0 & 1 & 3 & 7 & 14 & 21 & 30 \\
\hline \multicolumn{2}{|l|}{$\begin{array}{l}\text { Bottled product } \\
\text { mixture of } \mathrm{SH} \text { and } \mathrm{HCl}\end{array}$} & $\begin{array}{l}100.0^{\mathrm{A}} \\
(2.16)\end{array}$ & $\begin{array}{l}98.1^{\mathrm{A}} \\
(3.47)\end{array}$ & $\begin{array}{l}95.7^{\mathrm{A}} \\
(3.33)\end{array}$ & $\begin{array}{l}92.9^{\mathrm{A}} \\
(3.00)\end{array}$ & $\begin{array}{l}89.8^{\mathrm{A}} \\
(3.21)\end{array}$ & $\begin{array}{l}88.7^{\mathrm{A}} \\
(3.36)\end{array}$ & $\begin{array}{l}88.4^{\mathrm{A}} \\
(3.57)\end{array}$ \\
\hline \multicolumn{2}{|l|}{$\begin{array}{l}\text { Electrolysis type } \\
\text { at on-site generation }\end{array}$} & $\begin{array}{l}100.0^{\mathrm{A}} \\
(2.76)\end{array}$ & $\begin{array}{l}98.7^{\mathrm{A}} \\
(2.58)\end{array}$ & $\begin{array}{l}96.3^{\mathrm{A}} \\
(1.50)\end{array}$ & $\begin{array}{l}90.5^{\mathrm{A}} \\
(3.22)\end{array}$ & $\begin{array}{l}79.2^{\mathrm{B}} \\
(4.15)\end{array}$ & $\begin{array}{l}72.8^{\mathrm{C}} \\
(3.88)\end{array}$ & $\begin{array}{l}66.7^{\mathrm{D}} \\
(2.52)\end{array}$ \\
\hline \multirow{2}{*}{$\begin{array}{l}\mathrm{CO}_{2} \text { mixture type } \\
\text { at on-site generation }\end{array}$} & $120 \mathrm{ppm}$ & $\begin{array}{l}100.0^{\mathrm{A}} \\
(2.74)\end{array}$ & $\begin{array}{l}98.9^{\mathrm{A}} \\
(1.80)\end{array}$ & $\begin{array}{l}95.0^{\mathrm{A}} \\
(1.61)\end{array}$ & $\begin{array}{l}91.6^{\mathrm{A}} \\
(2.39)\end{array}$ & $\begin{array}{l}88.7^{\mathrm{A}} \\
(1.69)\end{array}$ & $\begin{array}{l}85.9^{\mathrm{A}} \\
(2.17)\end{array}$ & $\begin{array}{l}82.6^{\mathrm{B}} \\
(2.08)\end{array}$ \\
\hline & $200 \mathrm{ppm}$ & $\begin{array}{c}100.0^{\mathrm{A}} \\
(2.67)\end{array}$ & $\begin{array}{c}98.5^{\mathrm{A}} \\
(1.46)\end{array}$ & $\begin{array}{c}94.6^{\mathrm{A}} \\
(1.43)\end{array}$ & $\begin{array}{c}90.4^{\mathrm{A}} \\
(1.87)\end{array}$ & $\begin{array}{l}86.4^{\mathrm{A}} \\
(2.72)\end{array}$ & $\begin{array}{l}82.1^{\mathrm{B}} \\
(2.34)\end{array}$ & $\begin{array}{c}78.8^{\mathrm{C}} \\
(1.70)\end{array}$ \\
\hline
\end{tabular}

B. Storage at room temperature with shading

\begin{tabular}{|c|c|c|c|c|c|c|c|c|}
\hline \multirow{2}{*}{\multicolumn{2}{|c|}{$\%$ of RCC at day 0}} & \multicolumn{7}{|c|}{ Storage periods (day) } \\
\hline & & 0 & 1 & 3 & 7 & 14 & 21 & 30 \\
\hline \multicolumn{2}{|l|}{$\begin{array}{l}\text { Bottled product } \\
\text { mixture of } \mathrm{SH} \text { and } \mathrm{HCl}\end{array}$} & $\begin{array}{l}100.0^{\mathrm{A}} \\
(2.16)\end{array}$ & $\begin{array}{l}96.4^{\mathrm{AB}} \\
(3.31)\end{array}$ & $\begin{array}{l}92.1^{\mathrm{A}} \\
(3.11)\end{array}$ & $\begin{array}{l}88.6^{\mathrm{A}} \\
(3.37)\end{array}$ & $\begin{array}{l}83.2^{\mathrm{A}} \\
(3.31)\end{array}$ & $\begin{array}{l}81.5^{\mathrm{A}} \\
(3.57)\end{array}$ & $\begin{array}{l}79.1^{\mathrm{A}} \\
(3.07)\end{array}$ \\
\hline \multicolumn{2}{|l|}{$\begin{array}{l}\text { Electrolysis type } \\
\text { at on-site generation }\end{array}$} & $\begin{array}{l}100.0^{\mathrm{A}} \\
(2.76)\end{array}$ & $\begin{array}{l}93.8^{\mathrm{BC}} \\
(2.21)\end{array}$ & $\begin{array}{l}82.8^{\mathrm{C}} \\
(3.95)\end{array}$ & $\begin{array}{l}71.7^{\mathrm{C}} \\
(1.35)\end{array}$ & $\begin{array}{l}58.9^{\mathrm{D}} \\
(3.40)\end{array}$ & $\begin{array}{l}50.8^{\mathrm{D}} \\
(3.02)\end{array}$ & $\begin{array}{l}40.2^{\mathrm{D}} \\
(3.27)\end{array}$ \\
\hline \multirow{2}{*}{$\begin{array}{l}\mathrm{CO}_{2} \text { mixture type } \\
\text { at on-site generation }\end{array}$} & $120 \mathrm{ppm}$ & $\begin{array}{l}100.0^{\mathrm{A}} \\
(2.74)\end{array}$ & $\begin{array}{l}97.8^{\mathrm{A}} \\
(2.30)\end{array}$ & $\begin{array}{l}91.7^{\mathrm{A}} \\
(2.05)\end{array}$ & $\begin{array}{l}84.4^{\mathrm{B}} \\
(1.46)\end{array}$ & $\begin{array}{l}75.6^{\mathrm{B}} \\
(2.09)\end{array}$ & $\begin{array}{l}68.7^{\mathrm{B}} \\
(2.43)\end{array}$ & $\begin{array}{l}62.9^{\mathrm{B}} \\
(1.94)\end{array}$ \\
\hline & $200 \mathrm{ppm}$ & $\begin{array}{c}100.0^{\mathrm{A}} \\
(2.67)\end{array}$ & $\begin{array}{l}91.9^{\mathrm{C}} \\
(2.10)\end{array}$ & $\begin{array}{l}88.3^{\mathrm{B}} \\
(1.70)\end{array}$ & $\begin{array}{l}81.9^{\mathrm{B}} \\
(2.33)\end{array}$ & $\begin{array}{l}70.5^{\mathrm{C}} \\
(2.13)\end{array}$ & $\begin{array}{l}61.2^{\mathrm{C}} \\
(2.73)\end{array}$ & $\begin{array}{l}51.7^{\mathrm{C}} \\
(1.86)\end{array}$ \\
\hline
\end{tabular}

C. Storage at room temperature with lighting

\begin{tabular}{|c|c|c|c|c|c|c|c|c|}
\hline \multirow{2}{*}{\multicolumn{2}{|c|}{$\%$ of RCC at day 0}} & \multicolumn{7}{|c|}{ Storage periods (day) } \\
\hline & & 0 & 1 & 3 & 7 & 14 & 21 & 30 \\
\hline $\begin{array}{l}\text { Bottled product } \\
\text { mixture of } \mathrm{SH} \text { and } \mathrm{HC}\end{array}$ & & $\begin{array}{l}100.0^{\mathrm{A}} \\
(2.16)\end{array}$ & $\begin{array}{l}94.4^{\mathrm{A}} \\
(3.55)\end{array}$ & $\begin{array}{l}87.5^{\mathrm{A}} \\
(3.84)\end{array}$ & $\begin{array}{l}80.0^{\mathrm{A}} \\
(3.36)\end{array}$ & $\begin{array}{l}66.7^{\mathrm{A}} \\
(3.47)\end{array}$ & $\begin{array}{l}50.2^{\mathrm{A}} \\
(3.53)\end{array}$ & $\begin{array}{l}24.7^{\mathrm{A}} \\
(3.20)\end{array}$ \\
\hline $\begin{array}{l}\text { Electrolysis type } \\
\text { at on-site generation }\end{array}$ & & $\begin{array}{l}100.0^{\mathrm{A}} \\
(2.76)\end{array}$ & $\begin{array}{l}87.2^{\mathrm{B}} \\
(1.88)\end{array}$ & $\begin{array}{l}74.6^{\mathrm{C}} \\
(3.95)\end{array}$ & $\begin{array}{l}50.5^{\mathrm{C}} \\
(2.30)\end{array}$ & $\begin{array}{l}32.0^{\mathrm{C}} \\
(3.62)\end{array}$ & $\begin{array}{l}17.0^{\mathrm{D}} \\
(0.43)\end{array}$ & $\begin{array}{c}2.0^{\mathrm{C}} \\
(0.29)\end{array}$ \\
\hline \multirow{2}{*}{$\begin{array}{l}\mathrm{CO}_{2} \text { mixture type } \\
\text { at on-site generation }\end{array}$} & $120 \mathrm{ppm}$ & $\begin{array}{l}100.0^{\mathrm{A}} \\
(2.74)\end{array}$ & $\begin{array}{l}91.3^{\mathrm{A}} \\
(2.41)\end{array}$ & $\begin{array}{l}84.1^{\mathrm{AB}} \\
(2.55)\end{array}$ & $\begin{array}{l}69.4^{\mathrm{B}} \\
(2.64)\end{array}$ & $\begin{array}{l}48.7^{\mathrm{B}} \\
(2.99)\end{array}$ & $\begin{array}{l}28.5^{\mathrm{B}} \\
(2.52)\end{array}$ & $\begin{array}{l}8.8^{\mathrm{B}} \\
(1.54)\end{array}$ \\
\hline & 200 ppm & $\begin{array}{l}100.0^{\mathrm{A}} \\
(2.67)\end{array}$ & $\begin{array}{l}87.4^{\mathrm{B}} \\
(2.01)\end{array}$ & $\begin{array}{l}82.3^{\mathrm{B}} \\
(2.34)\end{array}$ & $\begin{array}{l}68.8^{\mathrm{B}} \\
(2.03)\end{array}$ & $\begin{array}{l}46.2^{\mathrm{B}} \\
(1.81)\end{array}$ & $\begin{array}{l}20.3^{\mathrm{C}} \\
(1.68)\end{array}$ & $\begin{array}{c}2.2^{\mathrm{C}} \\
(0.57)\end{array}$ \\
\hline
\end{tabular}

$n=8$ for each experimental condition.

Values are represented as percentage (\%) of day 0 residual chlorine concentration, and mean and (SD).

RCC; residual chlorine concentration, $\mathrm{SH}$; sodium hypochlorite.

Temperature:22.5 $\pm 0.83^{\circ} \mathrm{C}$, illumination (fluorescent lamp lighting): $2022.5 \pm 84.01 \mathrm{~lx}$, and UV intensity: $10.7 \pm 1.21 \mu \mathrm{W} / \mathrm{cm}^{2}$. Superscript letters denote statistically significant differences $(p<0.01)$ within the same storage periods under the same storage condition of different HAs. 
storage in RT-Shd. The concentration of EtOH exposed to LT at RT decreased by approximately $13 \%$.

\section{Bactericidal effects of disinfectants under the condition} with organic matter

$\mathrm{RCC}$ and $\mathrm{pH}$ of each reagent was measured immediately before the bactericidal experiment with bacteria, i.e., $S$. mutans, $S$. aureus, and $E$. coli. This experiment was performed in accordance with ASTM E2315-03 TimeKill test. Therefore, each bacterial solution in BHI medium, which was rich in protein and other organic matter, was already included at 5\% (1/20, 1:19) in each disinfectant treatment of the bactericidal experimental stage. Moreover, we evaluated the bactericidal effect of organic matter, i.e., additional 5\% NRS (total organic matter was $10 \%$ at each disinfectant treatment), on the colony formation (Tables 4, 5). There was no difference in the effectiveness of the disinfectant among each bacteria (Table 3). There was also no effect of NRS on colony formation of each bacteria (Table 4). It was completely disinfected without NRS in $60 \mathrm{~s}$-treatment of SH, bottled $\mathrm{HA}$ (200 ppm), $\mathrm{CO}_{2}$ type HA (both 120 ppm and 200 ppm) generated at on-site, and DA. When $5 \%$ NRS was added to each disinfectant, it was completely disinfected with $\mathrm{SH}$, bottled HA (200 ppm), $\mathrm{CO}_{2}$ mixture HA (200 ppm) generated at on-site, and DA. In the $30 \mathrm{~s}$-treatment of the disinfectant, $\mathrm{SH}$, bottled $\mathrm{HA}$ (200 ppm), $\mathrm{CO}_{2}$ type HA (200 ppm), and DA were able to completely kill each bacteria with or without the addition of NRS (Tables 4 $\mathrm{A}-\mathrm{C})$.

To investigate the bactericidal effect under more stringent conditions, the 10 s-treated bactericidal

Table 4 Inhibitory effects of disinfectants on colony formation of bacteria under the condition with normal rabbit serum A. Escherichia coli

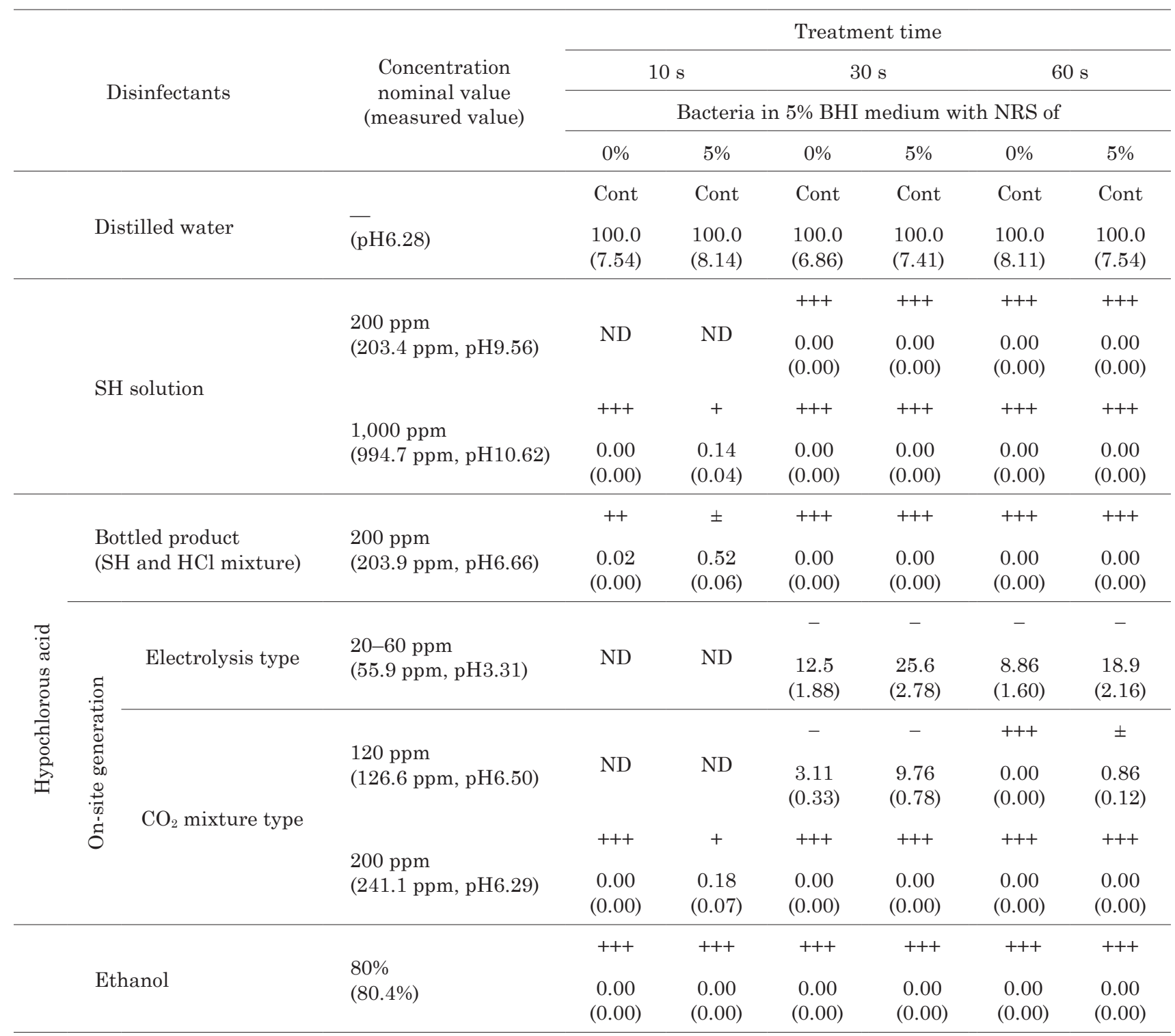


Table 4 continued

B. Streptococcus mutans

\begin{tabular}{|c|c|c|c|c|c|c|c|}
\hline \multirow{4}{*}{ 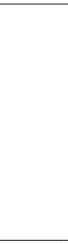 } & \multirow{4}{*}{\multicolumn{2}{|c|}{ Disinfectants }} & \multirow{4}{*}{$\begin{array}{l}\text { Concentration } \\
\text { nominal value } \\
\text { (measured value) }\end{array}$} & \multicolumn{4}{|c|}{ Treatment time } \\
\hline & & & & \multicolumn{2}{|c|}{$30 \mathrm{~s}$} & \multicolumn{2}{|c|}{$60 \mathrm{~s}$} \\
\hline & & & & \multicolumn{4}{|c|}{ Bacteria in $5 \%$ BHI medium with NRS of } \\
\hline & & & & $0 \%$ & $5 \%$ & $0 \%$ & $5 \%$ \\
\hline \multirow{2}{*}{\multicolumn{3}{|c|}{ Distilled water }} & & Cont & Cont & Cont & Cont \\
\hline & & & $\overline{(\mathrm{pH} 6.32)}$ & $\begin{array}{l}100.0 \\
(8.89)\end{array}$ & $\begin{array}{l}100.0 \\
(7.56)\end{array}$ & $\begin{array}{l}100.0 \\
(8.36)\end{array}$ & $\begin{array}{l}100.0 \\
(4.96)\end{array}$ \\
\hline \multirow{4}{*}{\multicolumn{3}{|c|}{ SH solution }} & & +++ & +++ & +++ & +++ \\
\hline & & & $\begin{array}{l}200 \mathrm{ppm} \\
(202.1 \mathrm{ppm}, \mathrm{pH} 9.53)\end{array}$ & $\begin{array}{c}0.00 \\
(0.00)\end{array}$ & $\begin{array}{c}0.00 \\
(0.00)\end{array}$ & $\begin{array}{c}0.00 \\
(0.00)\end{array}$ & $\begin{array}{c}0.00 \\
(0.00)\end{array}$ \\
\hline & & & & +++ & +++ & +++ & +++ \\
\hline & & & $\begin{array}{l}\text { 1,000 ppm } \\
\text { (993.2 ppm, pH10.45) }\end{array}$ & $\begin{array}{c}0.00 \\
(0.00)\end{array}$ & $\begin{array}{c}0.00 \\
(0.00)\end{array}$ & $\begin{array}{c}0.00 \\
(0.00)\end{array}$ & $\begin{array}{c}0.00 \\
(0.00)\end{array}$ \\
\hline \multirow{10}{*}{ 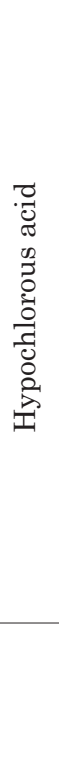 } & & & & +++ & +++ & +++ & +++ \\
\hline & & $\begin{array}{l}\text { led product } \\
\text { and } \mathrm{HCl} \text { mixture) }\end{array}$ & $\begin{array}{l}200 \text { ppm } \\
(207.6 \text { ppm, pH6.72) }\end{array}$ & $\begin{array}{c}0.00 \\
(0.00)\end{array}$ & $\begin{array}{c}0.00 \\
(0.00)\end{array}$ & $\begin{array}{c}0.00 \\
(0.00)\end{array}$ & $\begin{array}{c}0.00 \\
(0.00)\end{array}$ \\
\hline & \multirow{6}{*}{\multicolumn{2}{|c|}{ 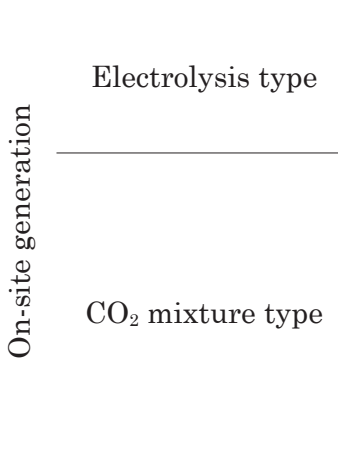 }} & & - & - & - & - \\
\hline & & & $\begin{array}{l}\text { 20-60 ppm } \\
(55.3 \text { ppm, pH3.21) }\end{array}$ & $\begin{array}{c}8.92 \\
(1.05)\end{array}$ & $\begin{array}{c}17.3 \\
(1.70)\end{array}$ & $\begin{array}{c}2.11 \\
(0.47)\end{array}$ & $\begin{array}{c}8.81 \\
(0.94)\end{array}$ \\
\hline & & & & \pm & - & +++ & + \\
\hline & & & $\begin{array}{l}120 \text { ppm } \\
(127.2 \mathrm{ppm}, \mathrm{pH} 6.54)\end{array}$ & $\begin{array}{c}0.71 \\
(0.53)\end{array}$ & $\begin{array}{c}7.61 \\
(0.52)\end{array}$ & $\begin{array}{c}0.00 \\
(0.00)\end{array}$ & $\begin{array}{c}0.47 \\
(0.07)\end{array}$ \\
\hline & & & & +++ & +++ & +++ & +++ \\
\hline & & & $\begin{array}{l}200 \text { ppm } \\
(240.4 \text { ppm, pH6.23) }\end{array}$ & $\begin{array}{c}0.00 \\
(0.00)\end{array}$ & $\begin{array}{c}0.00 \\
(0.00)\end{array}$ & $\begin{array}{c}0.00 \\
(0.00)\end{array}$ & $\begin{array}{c}0.00 \\
(0.00)\end{array}$ \\
\hline & \multirow{2}{*}{\multicolumn{2}{|c|}{ Ethanol }} & & +++ & +++ & +++ & +++ \\
\hline & & & $\begin{array}{l}80 \% \\
(80.6 \%)\end{array}$ & $\begin{array}{c}0.00 \\
(0.00)\end{array}$ & $\begin{array}{c}0.00 \\
(0.00)\end{array}$ & $\begin{array}{c}0.00 \\
(0.00)\end{array}$ & $\begin{array}{c}0.00 \\
(0.00)\end{array}$ \\
\hline
\end{tabular}

effect of $\mathrm{SH}$ (1,000 ppm), $\mathrm{CO}_{2}$ type $\mathrm{HA}$ (200 ppm), and DA was investigated using E.coli, which showed the most stable effects (Table 4). The results showed that all disinfectants were completely disinfected without NRS; however, colony formation of $E$. coli was observed approximately $0.14 \%$ in $\mathrm{SH}$ and $0.18 \%$ in $\mathrm{HA}$ in cases with the addition of $5 \%$ NRS. No colony formation was observed in DA, even in the presence of $5 \%$ NRS.

Rust of dental steel burs after repeated-disinfectant exposure

Rust on dental steel burs is commonly seen in clinical environment. The effect of the disinfectant on the rusting of steel burs was investigated (Fig. 4). The results showed that rust on the surface of steel burs occurred even in both DW and $80 \% \mathrm{EtOH}$, and the degree of rust was almost the same. The rust of $50 \mathrm{ppm}$
EL type $\mathrm{HA}$ and 120 ppm $\mathrm{CO}_{2}$ type $\mathrm{HA}$ treated dental burs was observed as the same level; however, $200 \mathrm{ppm}$ $\mathrm{CO}_{2}$ type HA-treatment produced more rust on dental burs than 50 ppm EL type HA and 120 ppm $\mathrm{CO}_{2}$ type HA-treatment. SH produced an even greater amount of rust compared to that of HA group. In DW, DA, and HA, the rust developed on the surface of dental steel burs; however, SH penetrated more deeply (Fig. 4).

\section{DISCUSSION}

The medical profession is a high-risk occupation for various infections, including COVID-1915,16). Disinfectants are important for prevention of infection, and the most widely used one in Japan is DA containing $76.9-81.4 \%\left(15^{\circ} \mathrm{C}\right)$ of EtOH. There has been a shortage of DA in Japan due to COVID-19. Therefore, surfactants, 
Table 4 continued

C. Staphylococcus aureus

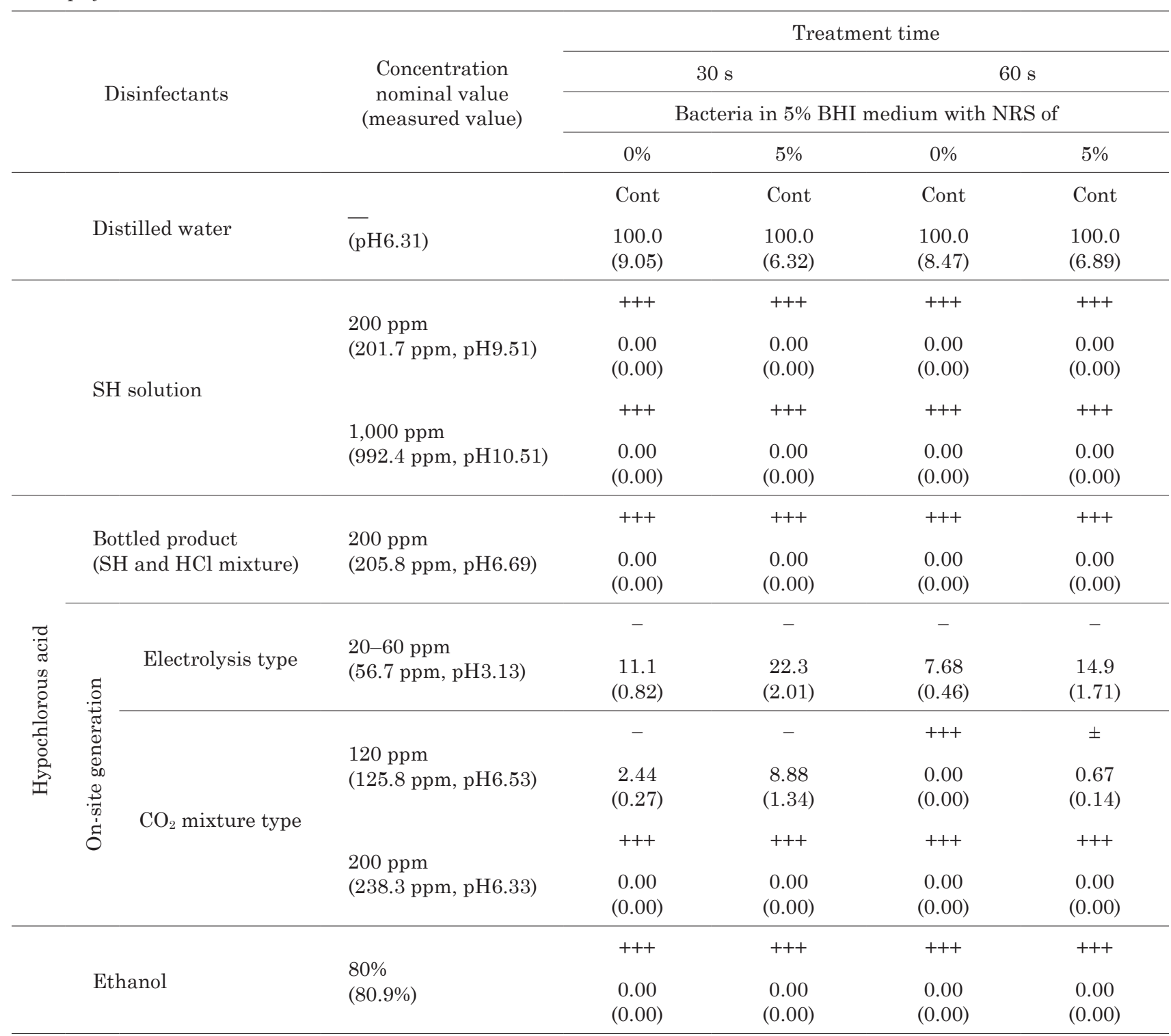

$\mathrm{n}=8$ for each experimental condition.

Values are represented as mean(\% of each sistilled water treatment group) and (SD).

$\mathrm{SH}$; sodium hypochlorite, $\mathrm{CO}_{2}$; carbon dioxide, BHI; brain heart infusion medium, NRS; normal rabbit serum, ND; not done, Cont; control

Bactericidal level (value \%; colony formation) $0 \%=+++, 0<++\leq 0.1 \%, 0.1<+\leq 0.5 \%, 0.5< \pm \leq 1.0 \%, 1 \%<-$.

$\mathrm{HA}$, and $\mathrm{SH}$ are suggested as its alternatives ${ }^{2}$. $\mathrm{HA}$ is used as a disinfectant worldwide, and the US EPA and CDC considers it a high-level disinfectant ${ }^{3,4}$. Moreover, HA is now recognized as a widely utilized agent for the management of blepharitis in the United States ${ }^{5,6}$. This simple chemical compound has a broad spectrum of activity and exhibits rapid kill kinetics against a wide range of bacterial and viral organisms ${ }^{6)}$. Ophthalmic formulations of HA are safe and extremely well tolerated by the patients. In this study, we focused on HA, which has a strong oxidation capacity with high safety, to investigate the bactericidal effects, and the degradation of the solution during various storage conditions to know how to use and store it correctly, and steel rust with disinfectant exposure, which were compared to those of DA.

DA is easy to obtain, and generally considered to have a good shelf life. However, it is oxidized to acetaldehyde, and $\mathrm{EtOH}$ concentration and bactericidal effects are reduced over time ${ }^{17)}$. As per the results of this experiment, volatile EtOH should be an extremely effective disinfectant in cases where the object is 
Table 5 Effects of NRS on colony formation of each bacteria immersed in DW with NRS

\begin{tabular}{|c|c|c|c|c|c|c|}
\hline \multirow{2}{*}{$\begin{array}{c}\text { Treatment time (s) } \\
\text { NRS (\%) }\end{array}$} & \multicolumn{2}{|c|}{10} & \multicolumn{2}{|c|}{30} & \multicolumn{2}{|c|}{60} \\
\hline & 0 & 5 & 0 & 5 & 0 & 5 \\
\hline Escherichia coli & $\begin{array}{l}100.0 \\
(7.54)\end{array}$ & $\begin{array}{c}99.2 \\
(6.75)\end{array}$ & $\begin{array}{l}100.0 \\
(6.86)\end{array}$ & $\begin{array}{l}101.1 \\
(7.12)\end{array}$ & $\begin{array}{l}100.0 \\
(8.11)\end{array}$ & $\begin{array}{c}98.9 \\
(6.50)\end{array}$ \\
\hline Streptococcus mutans & ND & ND & $\begin{array}{l}100.0 \\
(8.89)\end{array}$ & $\begin{array}{l}98.67 \\
(8.92)\end{array}$ & $\begin{array}{l}100.0 \\
(8.36)\end{array}$ & $\begin{array}{l}100.3 \\
(9.60)\end{array}$ \\
\hline Staphylococcus aureus & $\mathrm{ND}$ & ND & $\begin{array}{l}100.0 \\
(7.54)\end{array}$ & $\begin{array}{c}99.2 \\
(6.75)\end{array}$ & $\begin{array}{l}100.0 \\
(6.86)\end{array}$ & $\begin{array}{l}101.1 \\
(7.12)\end{array}$ \\
\hline
\end{tabular}

$n=8$ for each experimental condition. Values are mean(\% of each DW treatment group) and (SD).

NRS; normal rabbit serum, ND; not done

Superscript small and capital letters denote statistically significant differences $(p<0.01)$

between the NRS concentration in same treatment time, and between the treatment time in the same NRS concentration, respectively.

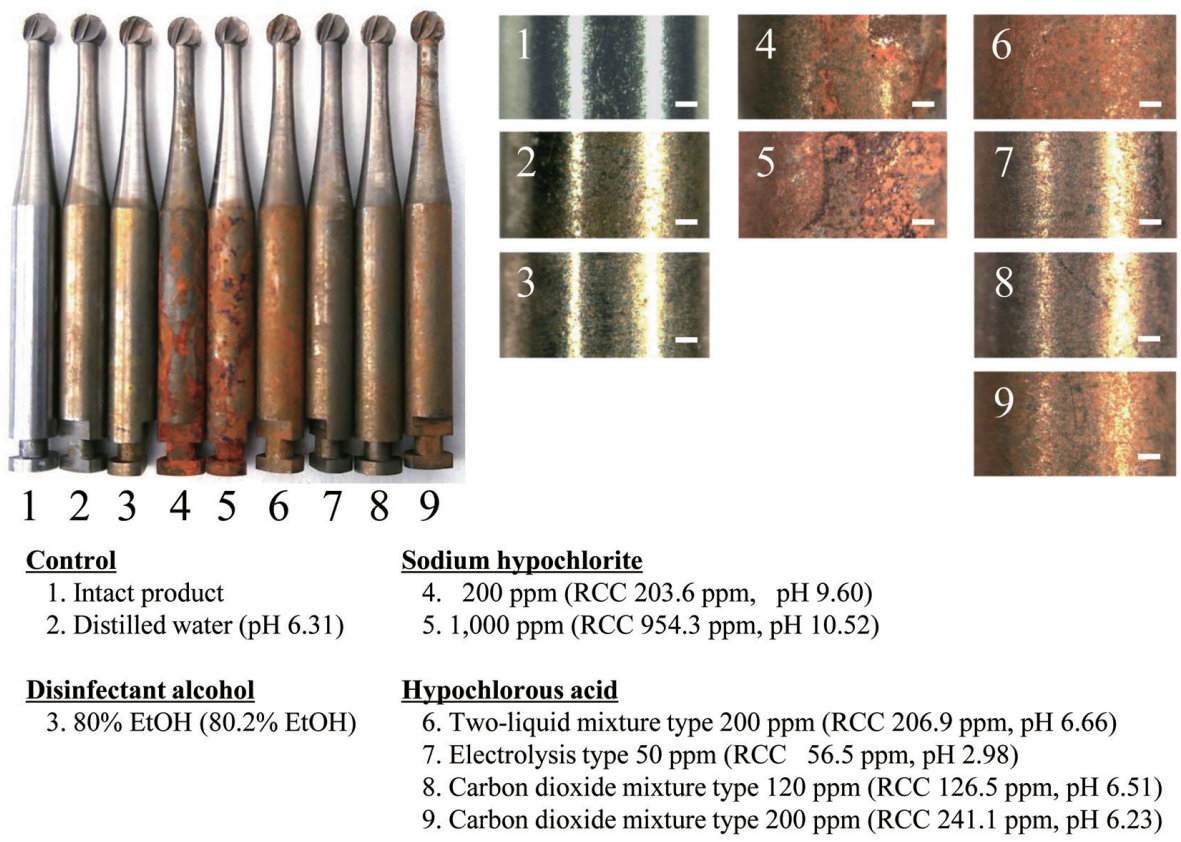

Fig. 4 Photographs of the surfaces of disinfectant-immersed dental steel burs. RCC; residual chlorine concentration, ( ); Measured values at start point of the experiments, White lines in the micrographs represent $100 \mu \mathrm{m}$.

immersed, but not wiped (Table 4). EtOH is most commonly used to disinfect objects and hands by direct application, which may lead to hand-roughening and allergy issues. Approximately $6-7 \%$ of individuals have allergic symptoms against $\mathrm{EtOH}^{18)}$. Furthermore, in addition to the hazards posed by the flammability of alcohol, adverse health effects are more likely with exposure to alcohol-based hand sanitizers with aspiration of volatiles and are worse than exposure to non-alcoholbased hand sanitizers, with a higher risk especially in children under 12 years of age ${ }^{19,20)}$. The World Health Organization has also noted the risks/hazards of alcoholbased hand rubs $^{21)}$.
SH is widely used as a disinfectant and bleach as it is readily available at a low cost. However, $\mathrm{SH}$ is strongly alkaline with its unique $\mathrm{Cl}$ smell, and safety for humans is a big problem. Therefore, attention was focused on HA. There are various types of HA, ranging from strongly acidic to neutral $\mathrm{pH}$, and it sterilizes bacteria at much lower concentration than SH. HA is capable of killing norovirus and spore bacteria, and it has less unpleasant $\mathrm{Cl}$ smell. However, HA is significantly degraded by UV light and heat ${ }^{10,11)}$; hence, it is difficult to guarantee the specifications of bottled HA (mainly the 2Mx type) sold in the market (Table 1$)^{12}$. Although the $2 \mathrm{Mx}$ type HA is easy to produce even at high concentrations with $\mathrm{pH}$ 
of acidity to neutral, it is difficult to produce at home, in general facilities, and medical institutions because of the possibility of generating $\mathrm{Cl}$ gas during the production process $(<\mathrm{pH} 4)$, which can be dangerous and potentially deadly. (Fig. 1b). The $2 \mathrm{Mx}$ type HA is more sensitive to light than to heat, and the $\mathrm{pH}$ drops significantly as the RCC drops (Tables 2B a) and 3). Light shading is the first condition, when storage of the $2 \mathrm{Mx}$ type $\mathrm{HA}$ is concerned, and it can be considered usable for 1 month after production under the light shading. However, as shown in Table 1, since it is supplied in bottles, the exact date of generation cannot be determined, so care must be taken when using it. Therefore, if HA is to be used in the medical field, it should be either the EL type or $\mathrm{CO}_{2}$ type generators; however, a proper generator, which is reasonably expensive, unlike the irresponsible cheap ones, is needed. Since HA produced by any generation method shows the same UV spectrum at the same $\mathrm{pH}^{22)}$, it is basically the same HA, although there are differences in by-products and degradation over time. The 2Mx type HA was the least likely to degrade under all circumstances, followed by the $\mathrm{CO}_{2}$ type, and the EL type was the most likely to degrade (Table 3 ).

The electrolysis method by a generator with bulkhead of ion exchange membrane (Fig. 1a), is difficult to produce high concentrations of $\mathrm{HA}$, and RCC is usually below 50-60 ppm with strong acidic $\mathrm{pH}^{23}$. Furthermore, since the electrolysis method used electrodes and ion exchange membranes, these degrade and dissolution with use caused a decrease in performance. This requires replacement of these electrodes and ion exchange membranes, which increases the cost. Instead, it is possible to produce HA with tap water and salt, which is cheap. The EL type HA is equally affected by both temperature and light, and the RCC decreases. The RCC also decreases linearly over time in refrigerated and light-shaded products. The $\mathrm{pH}$ does not change much during this process. When storing EL typed HA, refrigeration and shading from light is a prerequisite, and the maximum use is within 1 week (Tables $2 \mathrm{~B} \mathrm{~b}$ ) and 3). However, the $\mathrm{CO}_{2}$ mixing method generates $\mathrm{HA}$ with weak acid to neutral $\mathrm{pH}$, which required a $\mathrm{CO}_{2}$ tank, and tap water supply (Fig. 1c). Instead, high concentrations (hundreds of ppm) of HA can be easily generated by this type generator with sufficient flow rate without special maintenance. Therefore, the total running cost is lower than the EL type generator. $\mathrm{CO}_{2}$ type $\mathrm{HA}$ is equally affected by both temperature and light, and the RCC decreases. The RCC decreases linearly over time, even when refrigerated and shaded from light. Unlike the $2 \mathrm{Mx}$ type $\mathrm{HA}$, the $\mathrm{pH}$ does not change much or increases over time. When storing this HA, it must be refrigerated and shaded from light, and it should be used within a few weeks to 1 month (Tables $2 \mathrm{~B}$ and 3 ). In any case, the primary condition for HA generation is to be generated at the site where it is used. This is supported by the results of the degradation tests in this study. The results of this storage experiment also showed that shading is more important than temperature for the storage of $\mathrm{SH}$, which showed the same level of degradation over time as $2 \mathrm{Mx}$ type HA. Diluted $80 \% \mathrm{EtOH}$ is degraded more rapidly by lighting than by temperature. Alcohol concentration of unsealed $75 \%$ EtOH pads left for 21 days decreased to $47 \%$; hence, sealing the container is considered to be an important point for storing volatile $\mathrm{EtOH}^{17}$. SH and $\mathrm{EtOH}$ are not degraded at least within 30 days, if stored in a properly sealed shading container in a refrigerator.

The disinfectant effects of $\mathrm{SH}, \mathrm{HA}$, and $\mathrm{EtOH}$ on one bacteria in the oral cavity (S. mutans) and two bacteria associated with nosocomial infections ( $S$. aureus and $E$. coli) were studied under the conditions with or without organic matter, i.e., NRS. This experiment was performed in accordance with ASTM E2315-03 TimeKill test, which already included 5\% bacterial solution of protein-rich medium $(1 / 20,1: 19)$ of each disinfectant solution at the bactericidal experimental stage. The disinfectant is applied after removing the organic dirt from the surface of the object. The results of this study also showed a decrease in the disinfection of each disinfectant in the presence of organic matter, NRS. Disinfecting power of HA decreased in the presence of organic matter ${ }^{2,24,25)}$; therefore, the results of this study are reasonable. The results of this experiment showed insufficient disinfecting action of HA even at a concentration of $120 \mathrm{ppm}$, which is higher than the concentration at which the final joint statement of NITE, the Ministry of Economy, Trade, and Industry, and the Consumer Affairs Agency found HA to be effective at $80 \mathrm{ppm}$. The results of this study are more pragmatic, because the experimental conditions are more stringent than the usual testing. When the disinfectant effective in this experiment with a 30 -s action was examined with $E$. coli for a shorter 10 -s action, neither $1,000 \mathrm{ppm} \mathrm{SH}$ nor 200 ppm HA was sufficient for the disinfectant with addition of $5 \%$ NRS. These results indicate that effective disinfection requires removing dirt from the surface and then using the disinfectant, using a large amount of disinfectant to disinfect the surface while rinsing it off, or applying high concentrations of disinfectant to work for a certain amount of time (>30 s). However, it is not possible to completely remove the adhesion of organic matter in the actual clinical field. Hence, considering the human safety, it is important to use more than certain amount of freshly formed high concentration (>200 ppm) of $\mathrm{HA}$ and let it act for more than certain amount of time $(>30 \mathrm{~s})$.

As a result of the rusting test of dental cutting burs made of carbon steel, a small amount of rust was generated by DW and $80 \% \mathrm{EtOH}$, and $\mathrm{HA}$ of up to $100 \mathrm{ppm}$ (Fig. 4). In contrast, $200 \mathrm{ppm}$ produced a larger amount of rust, and 1,000 ppm SH induced a larger amount of rust. These agents should not be used especially for carbon steel, which is not a stainless steel that can suppress the rusting process as much as possible by the nonconductive film. EtOH does not cause metal corrosion frequently in a short period, whereas HA and SH start to corrode metal from the beginning ${ }^{24)}$. Therefore, EtOH and HA should be applied to metal instruments only after knowing their materials. 
Based on the results of this study, it was considered that presently HA with a certain level of concentration is suitable for use as an alternative disinfectant to DA. The results of this study indicated the following:

1. For flushing with running water: effective RCC of 100 ppm or higher with pH of 6.5 or lower

2. For wiping: effective RCC of $200 \mathrm{ppm}$ or higher with $\mathrm{pH}$ of 6.5 or lower

Therefore, the $\mathrm{CO}_{2}$ type $\mathrm{HA}$ generator is the most suitable for clinical environment, because it easily produces highly concentrated fresh HA safely at on-site. However, there are some disadvantages of the $\mathrm{CO}_{2}$ type HA generator, such as it is directly connected to the tap water supply, which makes installation cumbersome and requires installation work, and the need to connect a $\mathrm{CO}_{2}$ gas tank with periodic pressure checks.

HA is an extremely good disinfectant that is safe, economical, and effective, and can be an adequate substitute for DA. However, the use of $\mathrm{HA}$ with sufficient efficacy with minimal degradation requires compliance with proper storage and usage. There is an anion exchange method for generating $\mathrm{HA}$, which is less susceptible to degradation and can handle high concentrations; however, it is not possible to generate it on-site ${ }^{26)}$. Therefore, we are currently analyzing the newly developed light-resistant and rust-free $\mathrm{HA}^{26)}$, which can be produced on demand easily under any circumstances at on-site without any generators, especially for medical, dental, and welfare applications.

\section{CONCLUSIONS}

The results of this study show that the disinfection effects of high concentration of HA were comparable to that of DA. HA is considered more suitable for normal use in terms of practicality, safety, and user comfort than DA.

The basic requirement for ideal use of $\mathrm{HA}$ is that it should not be stored and should be used immediately after generation, and the remaining solution should be discarded. The basic and best way is to use HA generated on demand at on-site. Therefore, HA generated by a method that can be generated on demand at on-site without using a generator, or HA generator to produce effective highly concentrated HA (at least RCC of 200 ppm) at on-site is needed, for medical and dental clinical environment. Alternatively, as a compromise, another way would be to use HA generated by a less degrading generation method with storage under cool and dark place.

HA is considered as an excellent, suitable, safe, and easy-to-use disinfectant for normal use in medical institutions.

\section{ACKNOWLEDGMENTS}

The authors are grateful to the Department of Dental Materials Science, Nippon Dental University at Niigata for partially covering the costs of this study. The authors are also grateful to Mr. Yusuke TABEI (Hypochlorous acid Chemical Industrial Association) for useful advice and up-to-date, detailed information about disinfectants, including HA.

\section{CONFLICT OF INTEREST}

HA generator (KHM-1), and filter for tap water were provided by Renafine Inc..

\section{REFERENCES}

1) Kissler SM, Tedijanto C, Goldstein E, Grad YH, Lipsitch M. Projecting the transmission dynamics of SARS-CoV-2 through the postpandemic period. Science 2020; 368: 860-868.

2) National Institute of Technology and Evaluation (NITE), 2020, "Evaluation of the efficacy of alternative disinfection methods against novel coronavirus (Final Report)", available at: https://www.nite.go.jp/data/000111315.pdf (accessed X February 2021).

3) US Environmental Protection Agency, 2020, "List N for coronavirus (COVID-19), Disinfectants for use against SARS-CoV-2", available at: https://www.epa.gov/pesticideregistration/list-n-disinfectants-use-against-sars-cov-2. (accessed 12th May 2021).

4) Center for Disease Control and Prevention, 2018, "The National Institute for Occupational Safety and Health (NIOSH): High-level of disinfectants", available at: https:// www.cdc.gov/niosh/topics/healthcarehsps/disinfect.html. (accessed 12th May 2021).

5) Stroman DW, Mintun K, Epstein AB, Brimer CM, Patel CR, Branch JD, et al. Reduction in bacterial load using hypochlorous acid hygiene solution on ocular skin. Clin Ophthalmol 2017; 11: 707-714.

6) Block MS, Rowan BG. Hypochlorous acid: a review. J Oral Maxillofac Surg 2020; 78: 1461-1466.

7) Albrich JM, McCarthy CA, Hurst J. Biological reactivity of hypochlorous acid implications for microbicidal mechanisms of leukocyte myeloperoxidase. Proc Natl Acad Sci USA 1981; 78: 210-214.

8) Dukan S, Touati D. Hypochlorous acid stress in Escherichia coli: resistance, DNA damage, and comparison with hydrogen peroxide stress. J Bacteriol 1996; 178: 6145-6150.

9) McKenna SM, Davies KJA. The inhibition of bacterial growth by hypochlorous acid. Possible role in the bactericidal activity of phagocyte. Biochem J 1988; 254: 685-692.

10) Len S-V, Hung Y-C, Erickson M, Kim C. Ultraviolet spectrophotometric characterization and bactericidal properties of electrolyzed oxidizing water as influenced by amperage and pH. J Food Prot 2000; 63: 1534-1537.

11) Feng Y, Smith DW, Bolton JR. Photolysis of aqueous free chlorine species ( $\mathrm{HOCl}$ and $\mathrm{OCl}^{-}$) with $254 \mathrm{~nm}$ ultraviolet light. J Environ Eng Sci 2007; 6: 277-284.

12) Tomita T, Kikuchi K. In-vitro bactericidal and virusinactivating effects of various hand-wash and gargle products. Kansenshogaku Zasshi 2018; 92: 670-677.

13) Japanese Ministry of Health, Labour and Welfare, 2009, "Documents on the designation of hypochlorite water as a food additive", available at: https://www.mhlw.go.jp/ shingi/2009/08/dl/s0819-8m.pdf (accessed 12th May 2021).

14) Japanese Ministry of Health, Labour and Welfare, 2009, "Guidelines for infectious disease control in nursery schools", available at: https://www.mhlw.go.jp/bunya/kodomo/pdf/ hoiku02_0001.pdf (accessed 12th May 2021).

15) $\mathrm{Lu} \mathrm{M}, 2020$, "The front line: visualizing the occupations with the highest COVID-19 risk", available at: https:// www.visualcapitalist.com/the-front-line-visualizing-theoccupations-with-the-highest-covid-19-risk/ (accessed 12th May 2021). 
16) SoftBank Group Corp., 2020, "Preliminary results of antibody tests, etc". available at https://group.softbank/system/files/ pdf/antibodytest.pdf (accessed 12th May 2021).

17) Sato S, Kudo S, Kanamaru S, Saitoh Y, Yamauchi H, Tsushima R. Studies on temporal change of bactericidal activity of alcohol pad after preparation. Jpn J Infect Prev Contr 1991; 6: 35-39.

18) Stotts J, Ely WJ. Induction of human skin sensitization to ethanol. J Invest Dermatol 1977; 69: 219-222.

19) Loren Bonner L. CDC report calls attention to hand sanitizer risk in children. Pharmacy Today 2017; 23: 34.

20) Santos C, Kieszak S, Wang A, Law R, Schier J, Wolkin A. Reported adverse health effects in children from ingestion of alcohol-based hand sanitizers —United States, 2011-2014. MMWR 2017; 66: 223-226

21) WHO guidelines on hand hygiene in health care (advanced draft - World alliance for patient safety), global patient safety challenge 2005-2006: "Clean Care is Safer Care" available at https://www.who.int/gpsc/5may/tools/who_guidelines- handhygiene_summary.pdf (accessed 12th May 2021).

22) Nakagawara S, Goto T, Nara M, Ozawa Y, Hotta K, Arata $\mathrm{Y}$. Spectroscopic characterization and the $\mathrm{pH}$ dependence of bactericidal activity of the aqueous chlorine solution. Anal Sci 1998; 14: 691-698.

23) Aoki H, Miyasaka T, Ishida Y, Aoyagi Y, Miura D. Effects of hypochlorous acid electrolyzed water on dental alloys. J Jpn Dent Mater 2018, 37:171-178.

24) Takehara A, Urano H, Fukuzaki S. Cleaning of alumina fouled with bovine serum albumin by the combined use of gaseous ozone and alkaline electrolyzed water. Biocontrol Sci 2001; 6: 103-106

25) LeChevallier MW, Cawthon CD, Lee RG. Inactivation of biofilm bacteria. Appl Environ Microbiol 1988; 54: 2492 2499.

26) Kameda T, Tabei $Y$, Igawa J. Instruction manual for hypochlorous acid: a review for appropriate selection and usage for extremely effective infection prevention in a clinical environment. J Jpn Dent Assoc 2021; 74: 33-42. 